\title{
Health, Inequality, and Economic Development
}

\author{
Angus DEATON $^{1}$
}

\section{Introduction}

$\mathrm{S}$ UPPOSE THAT INCOME causes good health. People live longer and are healthier in rich countries than in poor countries, people live longer and are healthier than their grandparents and great-grandparents who lived in poorer times and, within a country at a moment in time, rich people live longer and are healthier than poor people. Suppose too that this relationship is concave, so that income has a larger effect on health and longevity among the poor than among the rich. Then income redistribution from rich to poor, within countries, or between countries, will improve population health (Samuel Preston 1975). Yet there may be more to it than that. Income inequality, or other related social inequalities with which it is correlated, may be directly hazardous to individual health. According to a recent body of literature, equal societies have more social cohesion, more solidarity, and less stress; they

\footnotetext{
${ }^{1}$ Research Program in Development Studies and Center for Health and Wellbeing, Princeton University. Based on a paper prepared for Working Group 1 of the WHO Commission on Macroeconomics and Health. I am grateful to Anne Case for many helpful discussions during the preparation of this paper and to George Alleyne, David Cutler, Sandy Jencks, Michael Marmot, Jim Smith, Duncan Thomas, Richard Wilkinson, and three referees for comments on earlier versions. I am grateful for financial support from the John D. and Catherine T. MacArthur Foundation and from the National Institute of Aging through grants to Princeton and to the NBER.
}

offer their citizens more public goods, more social support, and more social capital; and they satisfy humans' evolved preference for fairness. That equal societies are healthier is an argument particularly associated with Richard Wilkinson (1992, 1996, 2000), as well as the collection of papers edited by Ichiro Kawachi, Bruce Kennedy, and Wilkinson (1999). One study (John Lynch et al. 1998) goes so far as to claim that, in the United States in 1990, the loss of life from income inequality "is comparable to the combined loss of life from lung cancer, diabetes, motor vehicle crashes, HIV infection, suicide, and homicide in 1995." If even a fraction of this effect were real or if, more broadly, income distribution affects population health even indirectly, economic and fiscal policy has effects on well-being that are typically ignored by economists or policy makers. And if economists are skeptical of such mechanisms, many policy makers are not; shortly after being elected, British Prime Minister Tony Blair stated in Parliament that "there is no doubt that the published statistics show a link between income, inequality, and poor health."'

This paper explores the theoretical basis and empirical evidence for a connection between inequality and health, among poor as well as rich countries. The proposition that

\footnotetext{
${ }^{2}$ Quoted in Michaela Benzeval, Ken Judge, and Sue Shouls (2001).
} 
income inequality is an individual health risk was first proposed for wealthy countries that have passed through the epidemiological transition, where chronic diseases have replaced infectious diseases as the main cause of mortality. But as we shall see, many of the arguments that income inequality is a health risk are as plausible for poor as for rich countries and, in some cases, more so.

I devote a substantial portion of the paper to theory, albeit interspersed with evidence. With a few exceptions, the literature does not specify the precise mechanisms through which income inequality is supposed to affect health. In consequence, there is little guidance on exactly what evidence we should be examining, or whether the propositions are refutable at all. Section 2 lays out some of the possible stories, starting with the simple case in which health is affected by income, and there is no direct effect of inequality. This is sometimes referred to us the "absolute income hypothesis," to emphasize that it is income that matters for health, not income relative to other peoples' incomes, nor income inequality. A name that would be at least as good is the "poverty" hypothesis, that ill health is a consequence of low income, in the sense that more income improves health by more among those with low incomes than among those with high incomes. It is important to start by establishing the full range of implications for this simple case, and in particular what role is played by income inequality. I also discuss what happens when we make health depend, not on absolute income, but on relative income, and what this version of the relative income hypothesis implies for the relationship between health and inequality.

Much of the health-economics literature does not accept the existence of any causal effect running from income to health, except possibly through the purchase of health care, arguing that the correlation between them is driven in part by a causality running from health to income, and in part by third factors, such as education, or rates of time preference. For much of this paper, I shall take it as given that a causal link from income to health is at least part of the story, and follow the consequences. Even so, I include in section 2 a brief discussion of the topic, recognizing that an adequate discussion of the relationship between income and health would require a survey much longer than the present one.

I discuss a number of other theoretical links between inequality and health, including possible effects of income on investments in health and education, the two-way link between nutrition and earnings at low levels of income, and the arguable negative effects of inequality on the ability of the political process to deliver public goods. I also consider arguments that our evolutionary history predisposes us toward fairness, and sickens us when we live in unequal environments. Such an account can be made consistent with a story in which relative deprivation is a cause of ill health and according to which, within groups, inequality has no effect on health conditional on income, while across groups, both average income and income inequality determine health. Finally, I consider the important case in which income inequality is in part a consequence of ill health, so that policies that reduce the likelihood of sickness, shorten its duration, or ameliorate its effects on earnings can also narrow income inequalities. Some income inequality is a consequence of the fact that earnings cannot be completely insured against ill health, so that better health insurance is likely to help reduce inequalities in income. Better insurance will typically reduce inequalities, both in health and in income.

Section 3 turns to the evidence, most of which comes from developed economies. I review cross-country studies on adult mortality for rich countries and on child mortality for both rich and poor countries. A major question is whether the international data on income distribution is of sufficiently high quality to support the inferences that are 
being made. Better data, or, at least, more consistent data are available within countries, and some of the most interesting evidence on inequality and health comes from studies looking across areas and over time within developed countries, such as Britain, Canada, and the United States, and in a few poor countries. I also review the evidence from studies that link individual mortality and morbidity to the ambient level of income inequality, as well as those that study the links over time between income inequality and patterns of mortality.

My conclusion is that there is no direct link to ill health from income inequality per se; all else equal, individuals are no more likely to be sick or to die if they live in places or in periods where income inequality is higher. The raw correlations that exist in (some of the) data are most likely the result of factors other than income inequality, some of which are intimately linked to broader notions of inequality or unfairness. The fact that income inequality itself is not a health risk does not mean that inequalities more generally are not important, let alone that the social environment in which people live is irrelevant for their health. Indeed, I shall argue precisely the opposite. But we must narrow and focus our search if we are to make the leap from correlation to policy.

The literature that is reviewed in this paper comes from a number of fields other than economics, particularly epidemiology, public health, sociology, psychology, and history. Different fields have different styles of presenting theory and evidence, as well as different standards for what counts as credible evidence. Nevertheless, the ideas are often important and should not be dismissed by economists, if only because they are widely accepted by many policy makers and by scholars in other disciplines, and economists need to confront, not ignore, them. In this spirit, it is worth presenting material that is not fully worked out theoretically nor convincingly demonstrated empirically. Economists can make important contribu- tions to this work, and in turn are likely to benefit from other social scientists' sometimes well-argued skepticism of economists' methodologies and prejudices.

More broadly, ideas about income, income inequality, and health are important for welfare economics. Health is a component of well-being, so that if health were affected by income inequality, tax and transfer policies that affect the distribution of income would have effects that work, not only through the usual mechanisms-for example, through an equity-preferring socialwelfare function defined over levels of income or consumption-but also through individual levels of health. If income has a nonlinear effect on health, and even if there is no direct effect of income inequality on health, redistribution of income toward the poor will improve their average health by more than the loss of health among the rich. People who are income-poor are also healthpoor, so that seeing well-being as dependent on both income and health reveals wider disparities between rich and poor than are recognized by standard, income-based approaches.

\section{Theoretical Accounts of Income Inequality and Health}

\subsection{Individual, Group, and National Health}

\subsubsection{Health, Income, and Poverty}

Figure 1 shows a recent version of the Preston (1975) curve, the international relationship between life expectancy and national income in current purchasing-power parity dollars. Among the poorest countries, increases in average income are strongly associated with increases in life expectancy, but as income per head rises, the relationship flattens out, and is weaker or even absent among the richest countries. As Preston originally noted, if this relationship were also to characterize the relationship between mortality and income within countries, 


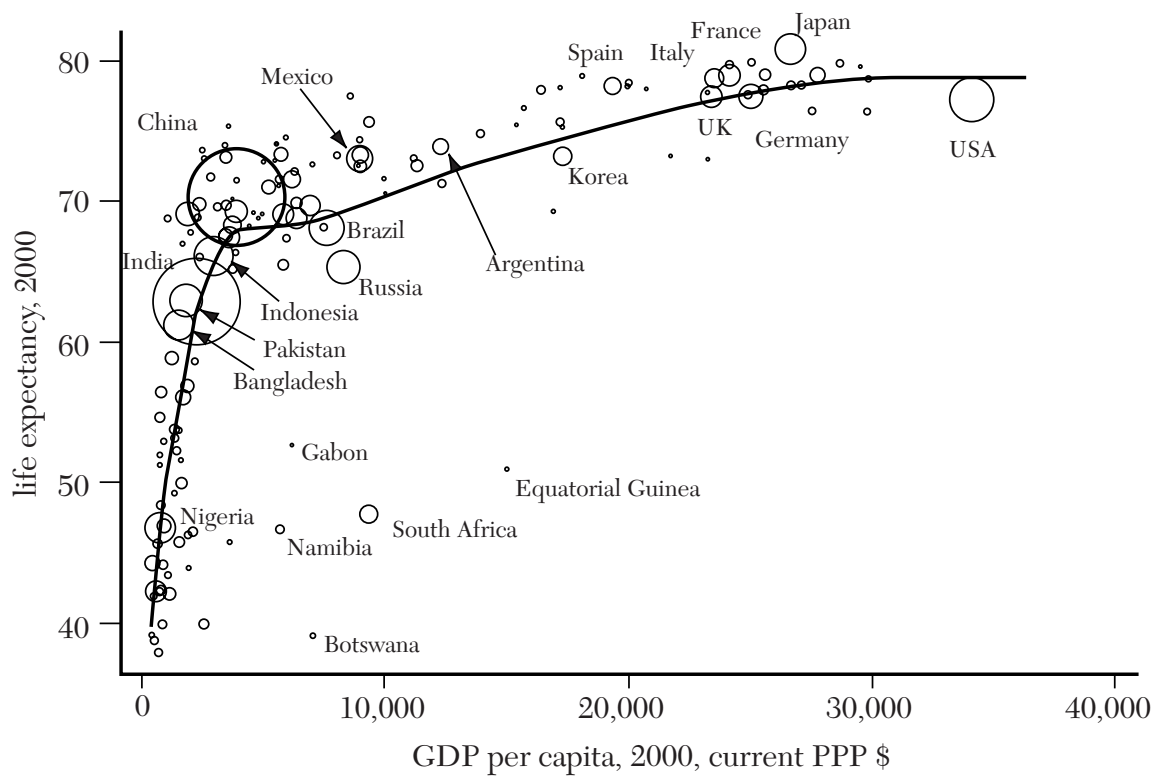

Figure 1. The Preston Curve: Life Expectancy versus GDP Per Capita

Source: World Development Indicators CD-ROM, World Bank (2002)

Note: Circles are proportional to population and some of the largest (or most interesting) countries are labeled. The solid line is a plot of a population-weighted nonparametric regression. Luxembourg, with per capita GDP of $\$ 50,061$ and life expectancy of 77.04 years, is excluded.

there would be a negative relationship across countries between income inequality and life expectancy. Redistribution of income from rich to poor, whether within or between countries, will increase the health of the poor more than it hurts the health of the rich, and thus improve average national or world health. Countries with particularly high income inequality, such as the United States, will have lower life expectancy than their average income would warrant.

As Preston surmised, there is indeed a relationship between income and mortality within rich countries, even those on the flat part of the international curve. Figure 2 was calculated from the National Longitudinal Mortality Survey in the United States. This is a national follow-up study of about 1.3 million people (with about three-quarters of a million people in the public release data) who were interviewed in a current population survey or in a census-related sample around 1980, and whose deaths over a follow-up period of 3,288 days were ascertained by matching to the National Death Index (see Eugene Rogot et al. 1992 for details). The survey collects each person's family income (within one of seven ranges) so that it is possible to link the probability of death during the follow-up to family income and other variables, the most important of which are sex and age. For adults between the ages of 18 and 85, the log odds of mortality are approximately linear in age, so a convenient way to summarize the data is to estimate a logit model for the probability of death in which age is entered linearly, together with a series of dummy variables for the income categories. 


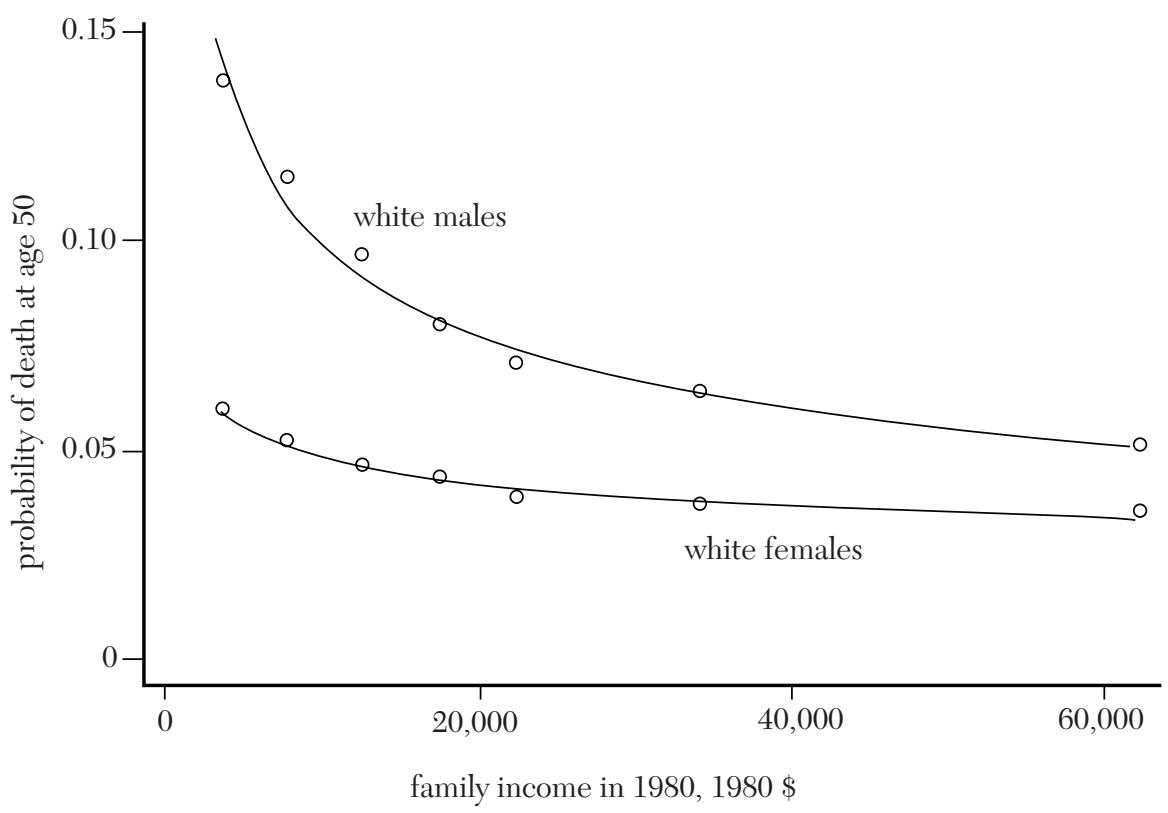

Figure 2. Age Adjusted Probability of Death and Family Income, National Longitudinal Mortality Study

Source: Author's calculations from public use sample of the NLMS.

Note: Probability of death is the probability that a 50-year-old man or woman at the time of interview (around 1980) died during the follow-up period of 3,288 days. Restricted to people aged 15 to 85 at the time of interview.

As it turns out, the log odds of mortality are close to being linear in the logarithm of family income, so that the probability of death is as illustrated in the figure, which shows, for men and women separately, the probabilities of a fifty-year old dying during the follow-up period. The protective effects of income are substantial; Rogot et al. calculate that people whose family income was more than $\$ 50,000$ in 1980 have a life expectancy that is about 25 percent longer than people whose family income was less than $\$ 5,000$. This difference is overestimated by the assumption that people stay in the same income class throughout their lives, but underestimated by the poor measurement of income in much of the NLMS, as well as by the fact that current income is likely a poor proxy for the longerterm measures of income that are presum- ably more relevant. For both men and women, the effect of income on mortality is greater among the poor than among the rich; that the curve for women appears less curved than the curve for men is an insignificant consequence of the choice of scale. If these curves come from a causal link between income and health, income redistribution will improve population health.

It is often useful to think of the redistributive story, not in terms of inequality, but in terms of poverty. If a country with a high average income has a great deal of income inequality, then there is a relatively large number of people with low income whose health is poor. Although figure 2 shows no poverty line below which income matters and above which it does not, it is at the bottom of the income distribution that the relationship 
between income and health really matters. And if a rich country has a lot of poor people, it will have low average health relative to its per capita income. To illustrate, Wilkinson (1989) looks at mortality differences by social class in Britain from 1921 to 1981, and argues that mortality fell most rapidly at times when income differentials were narrowed, particularly at times when incomes of the poor rose more rapidly than those of the rich, such as during World War II. Similarly, Amartya Sen (1999, figures 2.2 and 2.3) shows how life expectancy in England and Wales from 1901 to 1960 grew most rapidly in the decades 1911-21 (by 6.5 years) and 1940-51 (by 6.8 years), and more slowly at other times, 4 years in 1901-11, 2.4 years in 1921-31, 1.4 years in $1931-41$, and 2.8 years in 1951-60. Sen shows that the decadal rate of growth of GDP per capita is strongly negatively correlated with decadal increases in life expectancy and, like Wilkinson, focuses on the degree of sharing during the two wars, as well as on the direct nutritional and health interventions that took place during and immediately after the second war. Both wars brought well-paying employment opportunities to many people in Britain for the first time, including many women. Richard Hammond (1950) discusses how wartime food policy in the 1940s not only protected essential food supplies, but brought fresh milk and vitamins to working people to the extent that, unlike most of the citizens of Europe, their nutritional status improved during the war. Reductions in income inequality during the wars, if indeed they took place, marked an improvement in the conditions of the working people, among whom better incomes and better nutrition would have had the largest effects on mortality.

In contrast to these arguments, I shall argue in section 3.5 that it is not possible to link recent increases in income inequality in the United States and Britain to mortality changes. It should be noted, however, that recent increases in income inequality, though large enough by postwar standards, are probably not large relative to earlier compressions, particularly those associated with the world wars (see Peter Lindert 2000, and Claudia Goldin and Lawrence Katz 2001). They are also characterized more by increases in the incomes of the rich than by decreases in the incomes of the poor.

The fact that a concave relationship between health and income implies that average health is negatively associated with income inequality has come to be known in the literature as a "statistical artefact" (Hugh Gravelle 1998). The usage is designed to distinguish it from mechanisms in which income inequality has a direct effect on individual health, but it is unfortunate in suggesting that there is no real link between income inequality and health, and that redistributive policy cannot improve average population health. This is far from the case; if income causes health, and if there are diminishing returns, redistribution from rich to poor will improve average population health.

\subsubsection{Does Income Cause Health?}

The nonlinearity argument for income redistribution, in common with almost all of the literature in epidemiology and public health, takes it for granted that increases in income cause improvements in health and reductions in mortality. Yet Preston's original paper emphasized that income is only part of the story, and he shows that the curves have shifted upward over time, a movement that he attributes to improved public health measures, particularly in middle-income countries. And the 2000 Preston curve in figure 1 has developed a non-monotonicity around $\$ 5,000$, driven by the collapse of life expectancy in Russia, and by AIDS in Africa, particularly in South Africa; neither of these developments is income driven. Beyond this, much of the economics literature has been skeptical about any causal link from income to health, and instead tends to emphasize causality in the opposite direction, from 
good health to higher earnings, and from poor health to the inability to work and, in some countries, to running down assets to pay for care. Although these arguments are obviously correct in some cases, and no one seriously challenges that ill health is often a reason for early retirement from the workforce, they have been strongly resisted by many noneconomists, particularly in Britain; see Sally MacIntyre (1997) for an insightful discussion of the political background of these debates. Economists have also made the argument that the correlation reflects the operation of some third factor, particularly education (Michael Grossman 1972, 1975,2000 ), or preference factors such as discount rates. Those who are impatient or have poor self-control are likely both to fail to make investments to protect their health and to fail to acquire the education and skills that generate higher earnings (Victor Fuchs 1993). Such arguments also focus on the role of health-related behaviors, such as smoking, binge-drinking, or lack of exercise, which are correlated both with low income and poor health.

In private or partially private systems, money can also pay for more expensive health care, but this mechanism is often discounted, sometimes because of a general skepticism about the degree to which death can be postponed by medical care or, more specifically, because of doubts about the relative effectiveness of expensive over basic health care. It is also true that the relationship between income and mortality, the "gradient," exists in countries with and without public provision of health care; see Anton Kunst, Feikje Groenhof, and Johan Mackenbach (1998) for a review of European countries. Thomas McKeown (1976, 1979) famously demonstrated that, for disease after disease, the introduction of effective prophylaxis was not the primary factor driving historical declines in mortality, and the persuasiveness of his arguments has left a presumption, at least among medical sociologists and historical demographers, against the argument that differences in mortality across population groups are primarily driven by differences in access to or quality of health care. Yet McKeown's arguments, even if true historically, need not be true now, and the case against health care is far from well-established. Indeed, many studies today take it for granted that differences in health care are the primary and obvious reason for disparities in outcomes, for example "unequal treatment" of blacks and whites in the United States (Brian Smedley, Adrienne Stith, and Alan Nelson 2002).

For the purpose of the current discussion, I need only that there be some effect running from income to health, a position that has increasingly gained currency among economists in recent years; see for example the discussions in Jonathan Feinstein (1993), Preston and Paul Taubman (1994), and more recently, James Smith (1999). In Deaton (2002) I have tried to summarize my own position. An earlier, usefully skeptical review is by Alan Garber (1989). A full discussion of the theory and evidence relating income and health would occupy another review, at least the length of this one. Even so, it is worth emphasizing a few key points.

The literature outside of economics has documented many hundreds of cases of a positive correlation between health and some measure of socioeconomic status; the "modern" literature goes back to the eighteenth century, with precursors in ancient Rome and China; see Nancy Krieger (2001). One of the most influential of the current studies is of civil servants in Britain, the Whitehall study, which has documented substantial morbidity and mortality differences by administrative rank; see Michael Marmot, Martin Shipley, and Geoffrey Rose (1984), Marmot et al. (1991), and the more general discussions in Marmot (1994, 2002). This literature tends to see income as a "marker" for an underlying concept of socioeconomic status, which is treated as the underlying cause of health discrepancies. Because income is only one such marker, it 
is often treated interchangeably with wealth (or parts of wealth, such as vehicle ownership or housing), or with consumption, or earnings, or even with rank, power, social or occupational class, education, or even race and geography. Such a framework is not very useful for thinking about social policy as health policy-for example, in a simple tax system, a higher marginal rate of income tax will change disposable income, but will often have no effect on rank in the income distribution-nor does it take us very far in thinking about whether redistribution of income, as opposed to wealth, or even power, is likely to improve public health.

That said, there is an increasing number of studies that try to separate out different influences and confront economists' arguments about confounding by third factors. There are studies that look at the separate effects of both education and income. In the NLMS (and figure 2) the protective effects of income are not much affected by controlling for education (Irma Elo and Preston 1996; Deaton and Christina Paxson 2001a; and E. Backlund et al. 1999), and similar findings have come from other data sets (Evelyn Kitigawa and Philip Hauser 1973; Paula Lantz et al. 1998; Richard Rogers, Robert Hummer, and Charles Nam 2000). Income and education are also separately protective for self-reported health status (Jacob Nielsen 2002). Economists' skepticism about a direct role for income is supported by relationships between mortality, income, and education at the state or metropolitan statistical area level, where average education drives out average income, or even turns it into a risk factor (see Richard Austen, Irving Leveson, and Deborah Sarachek 1969; Joseph Newhouse and Lindy Friedlander 1980), a finding that continues to hold in more recent data (see Christopher Ruhm 2000; and Deaton and Darren Lubotsky 2003). The conflict between the individual and aggregate data remains unresolved. The relationship between income and health is reduced, but far from eliminated, by controlling for behavioral risk factors (in the Whitehall studies, which have full medical and behavioral data, only about a quarter of the association between rank and mortality is eliminated by controlling for risk factors), or for employment status.

The most difficult issue of all is sorting out the dual causality between income and health. In poor countries, where malnutrition remains a major issue, there is wide agreement that income has a direct causal effect; for excellent empirical evidence on the effects of South Africa's generous social pension, see Anne Case (2001, 2002). Many have argued the same about rich countries, emphasizing the negative effects of poverty and of poor housing, and the positive effects of not spending one's life worrying about money. Even malnutrition may still have effects in rich countries today; Gabriele Doblhammer and James Vaupel (2001) and Doblhammer (2002) have established a relationship between month of birth and remaining life-expectancy at age fifty (Austria, Denmark, Australia) and mean age at death (those who died between 1989 and 1997 in the United States). Those born in October and November do better than those born in March and April, although the seasonal pattern is reversed in the southern hemisphere (except for those who died in the south but were born in the north.) These effects are plausibly attributed to the effects of intrauterine nutrition more than half a century ago, particularly to the seasonal availability of fresh fruit and vegetables, and are indeed wearing off for more recently born cohorts. Theoretical mechanisms for such effects are developed in the work of David Barker (1994, 1995). The fetal origins ("womb with a view") hypothesis "states that fetal undernutrition in mid to late gestation, which leads to disproportionate fetal growth, programs later coronary heart disease" (Barker 1995, p.171). There is now extensive empirical evidence supporting these views, including evidence on the very 
long-lasting (or long-postponed) effects on health.

The studies of birth cohorts, particularly in Britain, have thrown up a wide range of dynamic effects between health and earnings, often operating with long lags. Panel data in Britain (British Household Panel Survey/BHPS) and the United States (Health and Retirement Survey/HRS) are currently being used to examine health and income dynamics. For example, in BHPS, Benzeval and Ken Judge (2001) find that controlling for initial (self-reported) health status reduces but does not eliminate the effect of current income or current health status. A more sophisticated approach, closely related to Granger causality testing, is employed by Peter Adams et al. (2003) using data from HRS; they find no causal link from wealth to health. This analysis, in particular, and the ability of "post hoc, propter hoc" inference to capture causality in general, has been seriously challenged by Fabrizia Mealli and Donald Rubin (2002). It is clear that there are influences between income and health that run in both directions, and that, in some cases, the lags can be as long as a human lifetime. In such circumstances, establishing clear causal patterns is a matter of great difficulty.

\subsubsection{Poverty, Health and the Direct and Indirect Effects of Inequality}

The absolute income (poverty) hypothesis tells us a good deal about how we can expect average income and income inequality to affect population health at different levels of development. At the most obvious, the effects of per capita income mirror those of individual income, and become less important the richer is the country. Eventually, we would expect income inequality to lose its effect too, but it is not enough that average income be high enough, we also need everyone's income to be high enough. The bottom tail of the income distribution has to be pulled up beyond the point at which income has much effect on health. Before that, there will still be health-diminishing poverty even in rich countries, so that income inequality will still matter as well as average income. In consequence, the absolute income or poverty hypothesis implies that, among the poorest countries, average income is what matters for population health, and income inequality is relatively less important. Among rich countries, average income is less important, and income inequality relatively more important. Eventually, neither will matter much for population health but, under plausible assumptions, the effect of income inequality relative to that of average income continues to grow as countries become richer. These implications of the absolute income hypothesis are important because it is often claimed that the differential effects of average income and income inequality on health change with economic development as described, and that the observation helps establish the case for a direct effect of inequality on health in rich countries. While the finding is certainly consistent with such an effect, it is also consistent with a simple model in which income has a larger effect on health among the poor.

Suppose that individual $i$ lives in country $s$, and that her health $h_{i s}$ is a quadratic function of her family income $y_{i s}$ so that if, for convenience, I write everything relative to worldwide means, signified by overbars, we have

$$
\begin{aligned}
h_{i s}-\bar{h}=\alpha+ & \beta\left(y_{i s}-\bar{y}\right) \\
& -\gamma\left(y_{i s}-\bar{y}\right)^{2}-\theta v_{s} .
\end{aligned}
$$

Income promotes health, but by less for the rich, so that both $\beta$ and $\gamma$ are positive. Income inequality, here represented by the variance $v_{s}$ of income around the country mean, $y_{s}$, is allowed to have a direct effect on health; I shall be particularly concerned with the case where $\theta$ is zero, so that the only effects of nonlinearity are the aggregation effects associated with the nonlinearity. Equation (1) is assumed to hold true everywhere, for all individuals, whether they live 
in poor or rich countries, and wherever they are in the epidemiological transition. Averaging (1) over everyone within each country, we get the cross-country relationship

$$
\begin{aligned}
h_{s}-\bar{h} & =\alpha+\beta\left(y_{s}-\bar{y}\right) \\
& -\gamma\left(y_{s}-\bar{y}\right)^{2}-(\gamma+\theta) v_{s}
\end{aligned}
$$

where variables subscripted by $s$ are population means. Even if $\theta$ is zero, the variance appears in (2) through the aggregation.

Equation (2) can be used to illustrate a number of points. First, consider the effect of economic development in the form of higher levels of $y_{s}$ on the derivatives of health with respect to average income and income inequality. The derivative with respect to $y_{s}$ is $\beta-2 \gamma\left(y_{s}-\bar{y}\right)$, which, since $\gamma$ is positive, decreases with average income. By contrast, the derivative with respect to $v_{s}$ is constant. As a result, as a country becomes richer and average income rises, the effect on population health of income inequality becomes more important relative to the effect on population health of average income. This is true whether or not $\theta$, the direct effect of inequality, is zero.

The second point illustrated by (2), due to Douglas Miller (2000), is that the parameters $\gamma$ and $\theta$ are both identified in the equation so that it is possible, at least in principle, to test for a direct effect of inequality using only aggregate data. Intuitively, this works because the curvature in the individual relationship (1) is transmitted to the aggregate relationship (2), so that it is possible, using only aggregate data, to eliminate the part of the inequality effect that works through the aggregation. Miller applies this technique to mortality differences across the U.S. states, and finds that the relationship between mortality and income inequality is entirely explained by the curvature in the aggregate relationship between average income and mortality, leaving no room for a direct effect of inequality. This result, however, is quite contrary to that of Michael Wolfson et al. (1999), who use the NLMS data to estimate the relationship between income and mortality at the individual level (as in figure 2), and then show that the implied relationship between income inequality and mortality across the states accounts for only a fraction of the actual relationship. I shall return to the state data in section 3.3 below, but the contradiction between these two sets of results most likely reflects a deeper difference in the relationship between income and mortality when estimated from individual and aggregate data.

The quadratic model is useful for illustrative purposes, but not very plausible, if only because it implies that increases in income will eventually reduce health. A more realistic model links individual health to a latent variable, itself a function of income, and assumes that death takes place when this latent variable falls below some critical value. Under suitable assumptions, such a formulation yields explicit predictions for the probability of death for individuals, as well as the fraction dying in communities, and the resulting equations provide a better way of linking population health to population income and income inequality. As before, I write $h_{i s}$ for the health of individual $i$ in population $s$, and assume that health is linear in the logarithm of individual income,

$$
h_{i s}=a+b \ln y_{i s}+d \omega_{s}+\epsilon_{i s}
$$

where the random term $\epsilon_{i s}$ is assumed to be normally distributed with mean zero and variance $\sigma^{2}$, and $\omega_{s}$ is the within-country variance of log income, so that, once again I allow for a possible direct effect of inequality on health. The individual dies when $h_{i s}$ falls below the critical level $c$. The probability that this happens, or the probability of death, is written $p_{\text {is }}$ which is

$$
\begin{aligned}
p_{i s}=p\left(\text { death } \mid y_{i s} \omega_{s}\right)= \\
\Phi\left(\frac{c-a-b \ln y_{i s}-d \omega_{s}}{\sigma}\right)
\end{aligned}
$$

where $\Phi$ is the distribution function of the standard normal. Suppose that, within each 
country $s$, the logarithm of income is normally distributed with mean $\mu_{s}$ variance $\omega_{s}$. We can then rewrite (3) as

$$
\begin{aligned}
h_{i s}=a+b \mu_{s}+d \omega_{s} & \\
& +b\left(\ln y_{i s}-\mu_{s}\right)+\epsilon_{i s}
\end{aligned}
$$

so that $p_{s}$, the fraction of people dying in the state, or the probability of death conditional on the state mean and variance of $\log$ income, can be written

$$
\begin{aligned}
p_{s} & =p\left(\text { death } \mid \mu_{s}, \omega_{s}\right) \\
& =\Phi\left(\frac{c-a-b \mu_{s}-d \omega_{s}}{\sigma \sqrt{1+b^{2} \omega_{s} / \sigma^{2}}}\right) .
\end{aligned}
$$

Equation (6) links population mortality rates to the population mean of log income, $\mu_{s}$, and the variance of log income, $\omega_{s}$.

The main points of (2) carry through to the more realistic (6). The parameter $d$ is identified in (6) from the aggregate data; even though the log variance appears in both the numerator and denominator, its coefficient in the latter is the same as the coefficient of mean income in the numerator. Second, suppose that $d$ is zero, and we differentiate, first with respect to $\mu_{s}$, and then with respect to $\omega_{s}$, it is readily shown that (a) both derivatives tend to zero as $\mu_{s}$ goes to infinity, and (b) that the ratio of the inequality derivative to the mean log income derivative grows linearly in the latter. As countries become sufficiently rich, and in the absence of a direct effect of income inequality, neither population mean income nor income inequality have any effect on population mortality rates. But the effect of income inequality relative to the effect of income is larger among richer countries. Once again, this has nothing to do with a direct effect of inequality on health.

\subsubsection{Relative Income, Absolute Income, and Inequality}

If income causes health, it is possible that health is determined, not by absolute income, but by income relative to some aspiration level, or relative to the incomes of oth- ers. Richard Easterlin (1975) long ago found evidence that happiness is independent of income in the long run, and health may follow the same pattern. That health depends on income relative to average incomes of one or more reference groups is what we might call a relative income hypothesis. This could happen in a number of different ways. One case is where relative income determines access to material goods, for example when the people who live in a town are the market for local land for housing, with the richest getting the hilltop plots with fine views, and the poorest getting the plots downwind of the smokestacks. The local housing case is an example where it is not money itself that is important, but rank, here determined by money. More generally, rank at work is important in determining how much control people have over their working lives and, as demonstrated in the Whitehall studies, the degree of control at work accounts for much of the relationship between occupational status and health (Marmot et al. 1997).

The relative income theory is consistent with an effect of income inequality, although it does not imply it. The distinction is of some importance, if only because a direct influence of inequality on health, as proposed by Wilkinson, is frequently labeled "the relative income hypothesis." The argument appears to be that, if health is lower for those whose income is relatively low, then higher inequality makes the poor even poorer in relative terms, and so worsens population health. In section 2.1.6 below, I shall develop a model in which just this happens, but the effect is not an automatic consequence of a relative income model.

Suppose that, as before, individuals are labeled $i$, but that we use $s$ to index the relevant comparison or reference group. An individual's health might then be above or below the population mean depending on whether her income is above or below the average income in the reference group. Hence, with $\beta$ positive, we might write: 


$$
h_{i s}=\bar{h}+\beta\left(y_{i s}-y_{s}\right) .
$$

For the group as a whole, group average health $h_{s}$ is just average health $\bar{h}$, which is the same for all groups, so that neither group income nor group income inequality has any effect on group health. This annihilation of the effect of income on health as we move from the individual to the group will always happen if the reference group is within the unit over which we are aggregating. For example, if reference groups are geographically local, average income will be unrelated to average health at the region, province, or state level. Such an account offers one explanation for why income might be related to health within groups, but not between them.

The relative income story is also consistent with a role for income inequality at the group level, and the mechanism is the same as for the absolute income hypothesis, the nonlinearity of the relationship between income, now relative income, and health. Again, an obvious example is provided by the quadratic version of equation (7), in which individual health depends on income relative to group income and the square of income relative to group income:

$$
h_{i s}=\bar{h}+\beta\left(y_{i s}-y_{s}\right)-\gamma\left(y_{i s}-y_{s}\right)^{2}
$$

When we average health over individuals within each group, the first term vanishes, as before, while the second term becomes the variance of income,

$$
h_{s}=\bar{h}-\gamma v_{s}
$$

This provides us with one possible account of the oft-cited phenomenon that was previously discussed, that within states or countries, individual health is related to individual income, while between them, average health is only weakly dependent on average income but is negatively related to income inequality.

Yet another possibility is that health is determined by rank in an income distribution. In the individual data, this hypothesis gener- ates a monotone increasing nonlinear relationship between income and health, and there will be associated inequality effects over aggregated groups. If rank is all that matters about income, higher income for everybody will have no effect on anyone's health. This rank hypothesis is worth noting for two reasons. First, rank is a plausible determinant of power, of social status, or of control over others, all of which have been associated with health. Second, rank is not necessarily affected by the usual redistributive policies. For example, consider a redistributive policy that raises the marginal tax rate and uses the proceeds to pay lump-sum benefits to everyone. Provided the elasticity of labor supply is greater than -1 , there will be no effect on rank; if A has more income than $\mathrm{B}$ before the change, she will have more after the change (Kevin Roberts 1981).

\subsubsection{The Impossibility of Identifying Reference Groups}

An immediate problem with the implementation of any model of relative income is the identification of the relevant reference group. In a few cases, such as the Whitehall civil servants, the reference group (or at least what is likely people's most important reference group) is a ready-made part of the design. More usually, reference groups are not clearly defined and people will often have multiple such groups, comparing themselves to their neighbors, to their coworkers, to those they meet in social and religious organizations, and to those they see on television or read about in newspapers. One way of dealing with this is to recognize that reference group incomes cannot be observed, and to work out the effects of the omission on the relationship between the two things that we can observe, health and income. As shown in Deaton (2001a), this procedure brings inequality back into the story even when it has no direct role.

Figure 3 illustrates the simple case where there are two groups, labeled "economists" 


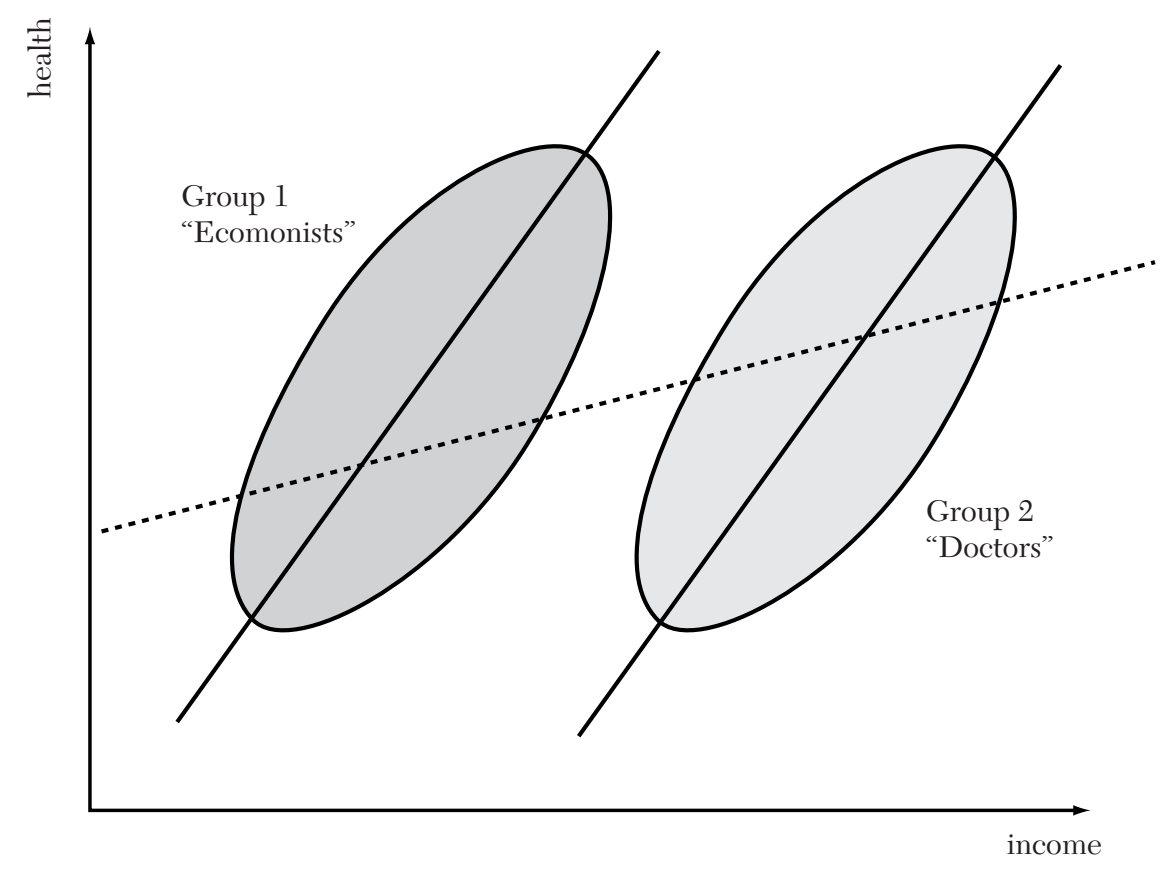

Figure 3. Health and Income in Two Reference Groups:

the Effects of Within- and Between-Group Inequality on the Gradient.

(on the left) and "doctors" on the right. Income is measured on the horizontal axis, health on the vertical axis. The two ellipses show where economists and doctors are located in terms of their health and incomes; members of each group are scattered within the two elliptical areas. Doctors have higher incomes than economists, and within each group, individual health depends on individual income relative to other members of the group. The two parallel steep lines show the relationships between income and health for each of the two groups. Although doctors have higher incomes than economists, their individual health is no better on average because their absolute income does not matter, only their income relative to other members of their group. Suppose that an epidemiologist analyzes the data on economists' and doctors' health, but without knowing which is which. When the data are pooled, the relationship between health and income is the flatter, broken line. By mixing the two groups, omitting the relevant information on group, the relationship is flattened out or attenuated.

Inequality comes into this story because the degree of flattening depends on the ratio of within-group income inequality to between-group income inequality. If doctors and economists are moved further apart, by moving the two ellipses horizontally away from each other, the broken line will become more attenuated. If within-group inequality is increased, holding the betweengroup difference fixed, so that the ellipses are stretched out along their individual income to health lines, the broken line will become steeper, increasing the gradient between income and health. The steepness of the gradient depends positively on the ratio of within- to between-group inequality. For example, in Whitehall, if there is only one reference group, that of British civil servants, 
the gradient of health with respect to income (or rank) is likely to be steeper than in a study containing a mixture of indistinguishable reference groups. More generally, if health depends on relative, not absolute, income, and there is an increase in income inequality that increases inequality within groups more than it increases it between groups, the slope of the gradient will increase.

In Deaton (2001a), I show that if health depends on relative income as in equation (7), so that

$$
h_{i s}=\bar{h}+\beta\left(y_{i s}-y_{s}\right)+\epsilon_{i s}
$$

where $\varepsilon_{i s}$ is a random term that ensures that there is a scatter around the line, then the expectation of health conditional on individual income, but unconditional on reference group income, takes the form:

$$
E\left(h_{i s} \mid y_{i s}\right)=\bar{h}+\frac{\beta \sigma_{w}^{2}}{\sigma_{w}^{2}+\sigma_{b}^{2}} y_{s}
$$

where $\sigma_{w}^{2}$ and $\sigma_{b}^{2}$ are the within- and between-group variances of income. The formula is the same as the attenuation bias formula for measurement error in regression analysis.

\subsubsection{Evolution, Equality, Deprivation, and Fairness}

It might easily be supposed that hierarchic, unequal societies are an inevitable part of the human condition. Yet for the vast majority of our evolutionary history, humans lived in hunter-gatherer groups that were not only not hierarchic, but aggressively egalitarian; see the survey of the literature by David Erdal and Andrew Whiten (1996). As has long been argued, perhaps first by McKeown (1976, 1979), human health is maximized when we live under the conditions under which we evolved, pursuing regular exercise (walking ten to fifteen miles a day, as foragers and hunters did), and eating low-fat, low-salt, low-meat, low-sugar, highfibre, largely vegetarian diets. By the same token, given that hierarchies and social in- equalities were unknown for most of our history, modern inequalities are likely to be a hazard to our health. This argument is forcefully and eloquently put by Wilkinson (2000).

That foraging groups were egalitarian appears to be widely agreed. Such arrangements could perhaps have come from lack of a technology for storing food. When a kill has been made, and the meat is too much to be consumed at once, sharing and subsequent reciprocity are the only mechanisms that can turn meat today into meat tomorrow. Humans, unlike other predatory species, lack a long-term ability to store glucose, and so cannot summon the energy to hunt after long periods without food, which may be why hunter-gatherer bands evolved in the first place (Arthur Robson 2002). Members of groups that enforced strict sharing would therefore have a survival advantage over members of those who did not, so that a preference for sharing, fairness, and reciprocation may be evolved attributes (see also Samuel Bowles and Herbert Gintis 1998). With the invention of settled agriculture, with the associated ability to fill and hold food in granaries, as well as to build herds of animals, egalitarian and reciprocal sharing was less efficient, and could give way to hierarchies within which rich and powerful individuals could dominate others. Although such systems and their industrial successors are vastly more productive than is foraging, the benefits come at the price of a nagging and health-compromising outrage over the loss of equality. And while humans will perhaps evolve to suit this new environment, we have only given up foraging for a very short time, only 10,000 to 20,000 years of our one- to two-million-year history. Adaptation to the new environment has its benefits, in terms of production, longevity, health, and population size, but it has a lingering cost that prevents our health from reaching its full potential.

Wilkinson and others have begun to weave together a plausible story of the 
processes that support such an account. Psychosocial stress is the main pathway through which inequality affects health. Wilkinson draws a contrast between societies in which relationships "are structured by low-stress affiliative strategies which foster social solidarity" on the one hand, and societies characterized by "much more stressful strategies of dominance, conflict and submission. Which social strategy predominates is mainly determined by how equal or unequal a society is" (Wilkinson 2000 , p. 4). Equality is seen as a precondition for the existence of stress-reducing networks of friendships, while inequality and relative deprivation are seen as compromising individual dignity, and promoting shame and violence. At the same time the biological mechanisms through which chronic stress compromises health are beginning to be understood; excellent surveys can be found in Robert Sapolsky (1998), Eric Brunner and Marmot (1999), and Wilkinson (2000, ch. 2.)

The story outlined above is persuasive in many respects. That the social environment in which we live helps determine our health is surely right, and the effects of psychosocial stress are now well-documented in both human (particularly Whitehall civil servant) and animal populations, where controlled experiments are possible. Yet it is less clear why income inequality is the only villain, or even one of the villains, in the piece. One attempt to explain is given in Deaton (2001b), which is extended in the following account. I treat income relative to other members of a reference group as the key variable, and hypothesize that stress on each individual depends on the differences between that individual's income and those of others in the group. The existence of incomes above you poses a threat, while incomes below you can be either costly, if you value fairness, or beneficial, if you derive pleasure from the status associated with having more income than others. A utility function with these proper- ties has been proposed by Ernst Fehr and Klaus Schmidt (FS) (1999), who note that people with such preferences, unlike purely selfish actors, are willing to give up their own resources to affect other people's outcomes. They show that the assumption that a fraction of the population has such preferences can account for a wide range of experimental and actual social behaviors.

The FS utility function is written

$$
\begin{aligned}
u(y)=y-\beta_{1} & \int_{y}^{\infty}(x-y) d F(x) \\
& +\beta_{2} \int_{0}^{y}(y-x) d F(x)
\end{aligned}
$$

where $\beta_{1}>0$ captures the extent to which it is harmful to have people with incomes above you, while $\beta_{2}$, which can be positive, negative, or zero, but in all cases greater than -1 , captures the benefits or costs that arise from the existence of people with incomes less than yours. FS assume that $\beta_{2}$ is negative, so that people with (12) are averse to people being either below or above them, caring about "fairness," or more precisely, "self-centered inequity aversion," but they note that almost all of their results are robust to allowing $\beta_{2}$ to be positive. $\beta_{2}$ is less than $\beta_{1}$ which guarantees that people prefer that their own incomes be higher.

If we note that the integral of $y-x$ over the range of $x$ is $y-\mu$, for mean income $\mu$, we can rewrite the FS utility function as

$$
\begin{array}{r}
u(y)=y+\beta_{2}(y-\mu)-\left(\beta_{1}-\beta_{2}\right) \times \\
\int_{y}^{\infty}(x-y) d F(x)=y+\beta_{2}(y-\mu) \\
-\left(\beta_{1}-\beta_{2}\right) \mu R(y)
\end{array}
$$

where $R y$ is the measure of relative deprivation, proposed by Shlomo Yitzhaki (1979). Relative deprivation is a term frequently used by Wilkinson in his discussions of social stress, and whose implications for health, also using the Yitzhaki measure, have been explored by Christine Eibner (2001). Although the meaning here is more specialized (and more precise) than that intended 
by Wilkinson, the formalization appears to be well-chosen, in that it generates many of the effects that he proposes. The derivative of health (utility) with respect to income is $1+\beta_{2}+\left(\beta_{1}-\beta_{2}\right)(1-F(y))$, which is positive, while the second derivative is $-\left(\beta_{1}-\beta_{2}\right) f(y)$ which is always negative. So if we think of health as proportional to utility, FS utility implies a concave relationship between income and health within groups. Because health is entirely determined by income, inequality has no effect on health conditional on income.

If we look at group health, and compute the average by integrating (13) over $y$, we obtain

$$
\begin{aligned}
u(y)=\int_{0}^{\infty} u(y) & d F(y) \\
& =\mu\left[1-\left(\beta_{1}-\beta_{2}\right) g\right]
\end{aligned}
$$

where $\mu$ is mean income, and $g$ is the gini coefficient of income inequality. Across groups, utility — or by supposition healthdepends positively on mean income but negatively on income inequality. (Note also that utility evaluated at mean income $\mu$ has the same form as (14) with the gini coefficient replaced by the relative mean deviation, sometimes called the Pietra or Robin Hood index, the last frequently used in the epidemiological literature. Equation (14) conforms almost exactly to Wilkinson's (1997) statement that "income inequality summarizes the health burden of individual relative deprivation."

In summary, this theory of mortality risk has three important implications: (i) within groups, health is a concave increasing function of income; (ii) conditional on an individual's income within the group, inequality does not matter for individual health; and (iii) for groups, average health depends positively on group income and negatively on group income inequality. The results of testing this theory are postponed to section 3 , where they can be presented in the context of other, related work on geographical mortality differences in the United States.

\subsection{Other Mechanisms, Other Inequalities}

\subsubsection{Credit Constraints, Health, and Income Inequality}

Income inequality may affect investment, including investments in health and education. If poor people are more likely to be credit constrained than rich people, if only because they have less collateral, redistribution from those without credit constraints to those with them may increase investment, a mechanism that has been explored in the recent literature on economic growth; see for example Roland Benabou (1996); Phillipe Aghion, Eve Caroli, and Cecilia GarcíaPeñalosa (1999); Pranab Bardhan, Bowles, and Gintis (2000). Relevant health investments may include taking a sick child to a hospital, paying for vaccinations, or even providing adequate nutrition; even if these have high rates of return over the long run, poor parents may lack the money to pay for them. Education is also relevant, in its own right, as an investment in human capital and higher earnings, but also because of its links with health. For example, Elo and Preston (1996) estimate that, around the world, a year of extra education reduces mortality rates by about 8 percent, half of which works through the effects of additional earnings, and half directly.

Figure 4 shows some relevant data on education for rural India. The 52nd round of the National Sample Survey collected data in 1995-96 on education enrolment and status of respondents. The graph shows the percentage of boys and girls aged from seven to twelve inclusive that are currently enrolled in school (as reported by the household in the survey) as a function of the logarithm of total household expenditure per head, a close proxy for income per head. The graphs are calculated using nonparametric regression using 20,307 boys and 17,321 girls aged seven to twelve. Boys are more likely to be in school than girls, both are more likely to be in school when they live in better-off households, and the effects 


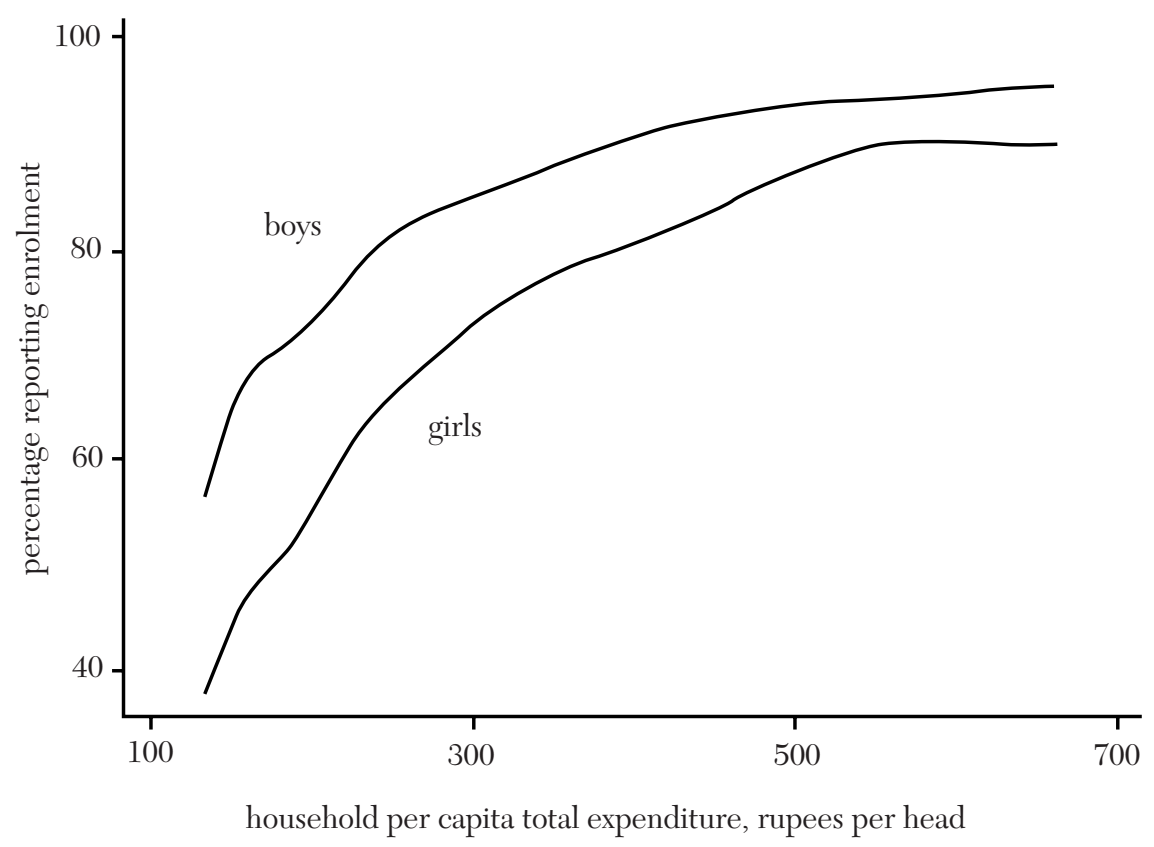

Figure 4. School Enrolment of Boys and Girls Aged 7 to 12 in Rural India, 1995-96.

Source: Author's calculations (locally weighted regressions) based on National Sample Survey data.

of additional resources are larger for girls than for boys. Although the slopes of the curve vary somewhat with per capita expenditure, they are flatter among better off households. In consequence, and with the usual caveats about omitted variables and causality, redistribution from richer to poorer households will increase the total percentage of children in school, and will increase girls' enrolment more than boys'. Education, in turn, is likely to improve health, not only of those receiving it, but of their children, particularly in the case of women.

Figure 5 shows some contrasting data on child vaccinations from the same Indian survey. As was the case for school enrolment, the fractions of children under five who have all three of the most important vaccinations (BCG, DPT, and OPV) is lower for poor than for rich households. However, unlike education, the slope is only slightly flatter among better-off than among poorer house- holds, so that this graph indicated no major effect of redistributing income on raising child vaccination rates. Nor is there any difference between vaccination rates of boys and girls.

These examples are only suggestive. The curves in figures 4 and 5 make no attempt to control for other factors - such as parental education, school quality, or health service provision - that are likely to be positively correlated with both household income and the outcome, so that the effects of income are almost certainly overstated. Nevertheless, the graphs illustrate that income redistribution may (or may not) increase health and educational investments in children, and may even differentially favor girls.

\subsubsection{Nutritional Wages, Health, and Inequality of Land}

The nutritional wage model provides an account of how inequality affects both health and earnings while explicitly recognizing that 


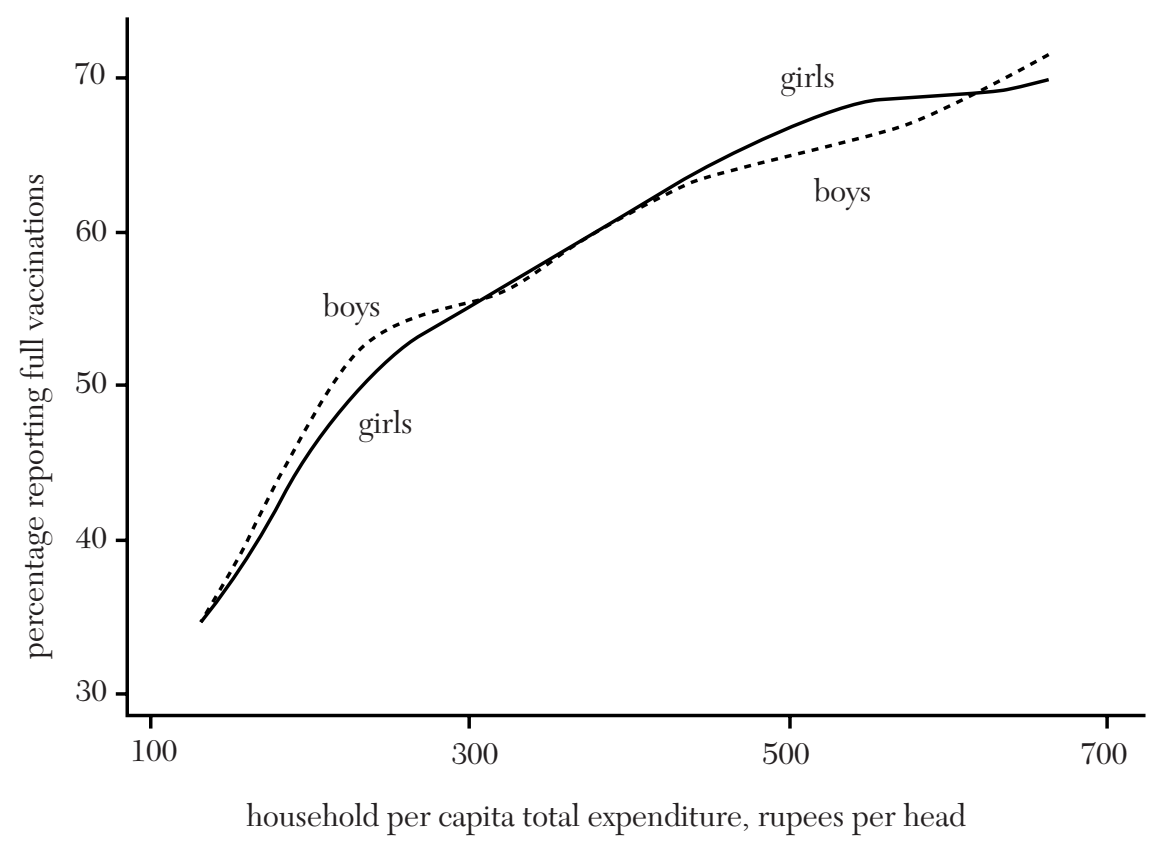

Figure 5. Vaccination Rates of Children Under 5 in Rural India, 1995-96.

Source: Author's calculations (locally weighted regressions) based on National Sample Survey data.

health and earnings are simultaneously determined. It pinpoints inequality in land holdings, not inequality in income, as the determinant of poor health, and provides the first of several examples of an important theme of this survey, that inequality in dimensions other than income may have an effect on health. The ideas go back to Harvey Leibenstein (1957), with the fundamental work by James Mirrlees (1975) and Joseph Stiglitz (1976); see Christopher Bliss and Nicholas Stern (1978) for a survey. That nutritional wage models can account for persistent poverty and destitution in poor countries is eloquently argued in Partha Dasgupta and Debraj Ray $(1986,1987)$ and Dasgupta (1993); an excellent textbook summary is provided by Ray (1998, ch. 13). According to this story, unemployed and destitute workers, even though they are willing to work for less than the wage being currently paid to employed workers, cannot un- derbid them because their undernourishment and poor health lowers their marginal product to make them unattractive hires even at the lower wage. More formally, there may be no combination of work and calorie consumption that is feasible for the worker and acceptable to the employer. Under such conditions, unemployment, and the chronic malnourishment and sickness associated with it, cannot be eliminated by decreasing the wage.

What is the role of inequality in this story? The root of the problem is seen in the distribution of land. If the destitute had sufficient land of their own, they would be able to meet their basic nutritional needs by growing food on small plots without having to work for wages. Seen this way, the problem of unemployment and malnutrition is a problem of landlessness, and can be resolved by redistributing land so as to give to every family a plot sufficient to guarantee 
their basic needs, and to enable them to participate gainfully in the labor market. Destitution is therefore seen as a problem that can be dealt with by a more equitable distribution of land.

The nutritional explanation of destitution and chronic malnutrition in India by Dasgupta and Ray is echoed by Robert Fogel's (1994) account of the economic and health history of Europe. He argues that, even at the end of the eighteenth century in England and France, food production was so low that, given its likely distribution over people, perhaps a fifth of the population was capable of no more than a few hours of light work each day. These people were chronically malnourished, were short in stature, and died young. Only the increase in agricultural productivity in the nineteenth century permitted an escape from this nutritional trap, and meant the beginning of the transition to better health, lower mortality, and longer life.

This story of nutrition and wages has much to commend it. It directly incorporates the two-way causality between health and earnings and provides a general equilibrium explanation of unemployment and poor health that has an obvious relevance to poor countries now as well as to the historical record in now-rich countries. It also pinpoints land reform as the appropriate redistributive policy prescription. Yet the predictions of the model have been challenged; see for example Hans Binswanger and Mark Rosenzweig (1984), Rosenzweig (1988, pp. 720-28), and John Strauss and Duncan Thomas (1998). Workers who are trapped by their low nutrition and inability to work would devote all their energies to finding food, and would have no energy for consuming anything other than food, for saving, or even for procreation (Mark Gersovitz 1983). And even in the poorest economies, food is typically too cheap relative to the wage rate to make the trap plausible. Shankar Subramanian and Deaton (1996) calculate that in rural Maharashtra in
1983, 2,000 calories (in the form of standard coarse cereals) could be purchased for less than 5 percent of the day wage, a finding that is consistent with the observation that poor agricultural workers in India typically eat their fill of cheap calories at the end of the work day; see also Anand Swamy (1997). With food so cheap, the nutritional wage trap seems too easy to escape. More broadly, the model does not always draw a sufficiently clear distinction between nutrition, which comes from the food that can be bought for money, and nutritional status, which depends on disease as well as on nutritional inputs. A plentiful supply of food will not nourish someone whose drinking water and food are contaminated, and chronic malnutrition typically needs to be addressed through public health measures as well as by increasing the supply of food. This criticism applies, not only to the nutritional wage theory as an account of destitution in poor countries, but also to McKeown (1976) and Fogel's (1994) arguments about the historical importance of nutrition; see particularly Preston (1996).

\subsubsection{Public Goods and Political Inequality}

While the nutritional wage story pinpoints inequality in land holdings as a cause of poor health, another line of literature sees the political process as a route through which income and other inequalities can affect health. One story is that heterogeneity in preferences makes it more difficult for people to agree on the provision of public goods, such as health, water supply, waste disposal, education and police. Such mechanisms have long been recognized in the literature on political economy, and a simple but suggestive account has been provided by Alberto Alesina, Reza Baqir, and William Easterly (1999). They point out that the average value of public good to members of a community diminishes with the heterogeneity of their preferences, a heterogeneity that could be located in racial, income, or geographical differences. Provision is therefore 
likely to be lower where heterogeneity is greater. Although they note the potential application to income inequality, Alesina, Baqir, and Easterly think of their model as applying to racial divisions in the United States, and to ethnic fractionalization more widely, a variable that often appears to have negative consequences in cross-country growth studies. In the context of the cities and counties of the United States examined by Alesina et al., ethnic fractionalization is closely related to the fraction of the population that is black, which is positively related to total spending, but negatively related to the shares in spending of "productive" public goods, such as health, roads, and education. For health, the total effect offsets the share effect, so that the absolute amount of health spending is positively associated with fractionalization. Income inequality is included in the models, although the results are not presented in the paper. However, I understand from one of the authors that the effects vary from model to model and that there are no robust negative effects of inequality on either total spending or its distribution. However, it might also be noted that Robert Putnam (1983), in his study of social capital in Italy, also sees equality as an important element in a well-functioning civic community.

Simon Szreter (1988) has provided a persuasive account of politics and sanitation in Britain in the mid-nineteenth century; see also Easterlin (1996). The urbanization of population associated with the industrial revolution led to a sharp reduction in public health, with mortality higher in cities than in the countryside, and a decline in overall life expectancy. Urban populations often had no access to clean water, and no facilities for disposal of human and other wastes, which were allowed to accumulate as a perpetual hazard to health. Crowding aided the transmission of infectious diseases, some of which can only be sustained in populations above a critical size. Pollution from smoke and other factory discharges contaminated the atmosphere and the environment. Yet many cities, in Britain and in Europe, were slow to address these problems, even when the necessary policies were well understood. Although the germ theory of disease was generally accepted only after 1870 , earlier explanations, such as the "miasma" theory, also emphasized the importance of cleaning up the environment. And while money is always a factor limiting public construction, these were periods of relatively rapid economic growth. Indeed, the coexistence of rapid economic growth and mortality increase (as well as a decrease in stature) during this period is regarded as something of a puzzle by economic historians-such as Michael Haines and Hallie Kintner (2000), Roger Schofield and David Reher (1991), and Fogel (1997) — who are typically so confident of the link between health and incomes that they often use measures of the former — such as stature- as reliable indicators of the latter (Richard Steckel 1995).

Szreter (1988) argues that the key to understanding the mortality transition in England lies in local politics. Although the industrializing cities were in fact well supplied with fresh water, it was used for commercial purposes, not supplied to homes. And the new entrepreneurial class, rich though it was, saw no point in spending each others' money for public sanitation which had no obvious commercial benefit. It was only after political reform, and particularly the limited political emancipation of working men, that new political coalitions could develop that made sanitation and public health a priority.

This is a story of nineteenth-century England, not of the world today, and it is about political, not income, inequality. Yet there is a marked parallel with the effects of civil rights legislation in the American South in the late 1960s. Douglas Almond, Ken Chay, and Michael Greenstone (2001), using detailed data from Mississippi, document that, prior to 1965 , hospitals were strictly segregated by race and that, especially in 
rural areas, there was limited access for black mothers and their infants. Federal actions, i.e., the 1963 court decision outlawing "separate but equal" clauses in federal hospital construction, and the 1964 Civil Rights Act, made segregation illegal, but it was the passage of Medicare in 1965, which prohibited Medicare funding to segregated hospitals, that effectively enforced desegregation. Almond, Chay, and Greenstone show that, from 1965 to 1971, there was a large reduction in black post-neo-natal infant mortality rates, particularly in conditions amenable to treatment, such as diarrhea and pneumonia, and that this period saw the only sustained narrowing of the gap in black-white infant mortality rates after 1950 .

In the story of Britain in the nineteenth century, the central actors in the plot are the Reform Acts and their (limited) extension of democracy which may or may not have (directly) reduced income inequality, but certainly reduced political inequality. In the story of the South, the civil rights legislation not only improved the health of African Americans, it also markedly improved their incomes relative to those of whites (John Donohue and James Heckman 1991; and David Card and Alan Krueger 1993). Reducing political inequality — that some can vote and others cannot, or some can get access to schools, hospitals or jobs while others cannot-is not only valuable in its own right, it also helps reduce other inequalities, in health, incomes, and education, in accord with the general thesis of Amartya Sen (1999). In a contemporary context, it is hard not to see political action, or at least the lack of it, as one of the reasons behind the low level of provision of schools and clinics in Indian villages. Rhagobendra Chattopadhyay and Esther Duflo's (2001) work in India shows how the mandated representation of women as leaders of village councils (in a randomly selected third of all Indian villages) has led to small but perceptible gains in public goods important to women and children, particularly water, fuel, and roads (whose construction provides employment opportunities for women) though, perhaps surprisingly, not in the limited amount of preschool education that is under panchayat control.

The work on villages in India, on nineteenth-century Britain, and on cities in the United States all point to the possible importance for health of political arrangements, and in particular to the consequences of inequalities in political power. Once again, the story is not about income inequality per se, though income inequality can hardly be unrelated to political inequality. But by taking a narrow focus on income inequality, we may be missing the inequalities that have the largest effect on health.

\subsection{Income Inequality as a Consequence of Ill Health}

Most of this section has started from the position that income causes health, developing the consequences for the relationship between income inequality and health. But health also causes income, and policies that directly affect health are likely to have effects on income inequality.

When interactions between income and health are important, the distribution of income will depend on the level and distribution of health. Any measure that reduces the spread of health conditions across the population, or improves the health environment, will narrow the distribution of income. Health shocks are important determinants of earnings and consumption in developing countries; see for example Paul Gertler and Jonathan Gruber (2002). In some countries health care expenses can be large relative to income or wealth (Adam Wagstaff 2002). In agricultural villages around the world, the poorest people are often those who cannot work as a result of some long-term disability or injury. Anything that helps people recover more rapidly from an illness will reduce the persistence of ill health, which reduces the long-term variance of health across the population. Better insurance arrangements, or better and more widespread clinics are 
obvious candidates to reduce such persistence, and so will not only improve population health (if they work at all), but also improve the distribution of income. Clean water, whose lack affects the poor more than the rich, will improve the incomes of the poor relative to the rich, and reduce income inequality. Malaria eradication campaigns and vaccination drives will have the same effect, not only improving population health, but also narrowing the distribution of income. This would be true even in a Lewis world in which there is an unlimited supply of labor at the subsistence wage. Better health may not improve the wage rate, and cannot do so under the Lewis assumption, but it can enable more people to work at that wage.

Once again, a simple formal model illustrates these points. Suppose that health and income satisfy the following equations:

$$
\begin{aligned}
& h_{t}=\alpha_{1}+\beta_{1} h_{t-1}+\gamma_{1} y_{t}+\epsilon_{1 t} \\
& y_{t}=\alpha_{2}+\beta_{2} h_{t}+\epsilon_{2 t}
\end{aligned}
$$

where $\varepsilon_{1 t}$ and $\varepsilon_{2 t}$ are stochastic shocks to health, each with zero mean, variances $\sigma_{11}$ and $\sigma_{22}$ and covariance $\sigma_{12}$ For the process to be stationary, I assume that $0 \leq \beta_{1}<1$. The conceptual experiment here of a group of identical people, who differ only in the random shocks that they receive to their incomes and health. These shocks are drawn from the same joint distribution, but independently across people. In such circumstances, the joint distribution of health and income across people is the same as the long-run time-series distribution of health and income from (15). It would be straightforward to introduce heterogeneity by making the parameters individual specific and, if the health and income shocks are distributed independently of the individual effects, the inequality from the dynamics can be added to the inequality from the heterogeneity. While stationarity is not realistic for finitely-lived people, it helps us isolate the contribution of random shocks to inequality.
The parameters in (16) can be thought of in terms of the various policies that might affect them. The variance of the health shock, $\sigma_{11}$, captures the health environment, and would be reduced by vector eradication campaigns, cleaning up the environment, or more comprehensive vaccinations. The parameter $\beta_{1}$ which is non-negative, controls the speed of the healing process once health has been compromised so that, for example, better health insurance and better healthcare would reduce $\beta_{1}$. The parameter $\beta_{2}$ which is positive, controls the effect of health on income. Disability insurance, which limits the effects of health on income, would decrease $\beta_{2}$, towards zero. If we take income to be net of health care expenses, $\beta_{2}$ will also reflect the costs of health care, and better health insurance, like disability insurance, will decrease it towards zero. The parameter $\gamma_{1}$ controls the direct causal link from income to health and, for the purposes of the argument, I shall assume it is zero so as to examine the effects of health on income inequality in the absence of any link from income to health.

We can use (15) to calculate the variances and covariance of income and health. In particular

$$
\operatorname{var}(y)=\sigma_{22}+\frac{\beta_{2}^{2} \sigma_{11}}{1-\beta_{1}^{2}}
$$

so that the variance of income is the variance of the income innovation plus a term that depends on the health environment and the insurance system. A reduction in the variance of health shocks-vector control, for example-reduces income inequality. So do improvements in health care, in health insurance, and in disability insurance. Places that have more of these policies in place will have better health and a more equal distribution of income. Even without any causal link from income to health, the regression coefficient of health on income (the gradient) is positive, and can be written

$$
b=\frac{\operatorname{cov}(h y)}{\operatorname{var}(y)}=\frac{\beta_{2} \sigma_{11}}{\beta_{2}^{2} \sigma_{11}+\sigma_{22}\left(1-\beta_{1}^{2}\right)}
$$


This gradient is larger the larger is the variance of the health shock relative to that of the income shock, and is smaller the more effective is the healthcare and health insurance system.

Income differences between countries are also affected by their differences in population health. In consequence, the speed at which new health technology is transmitted from the industrialized to developing countries affects their relative population healths as well as their relative incomes; see Jeffrey Sachs (2001). Current debates about international pricing of drugs and patent protection are important in this context. Whether the faster transmission of drugs and vaccines will improve the distribution of income within poor countries depends on the prevalence of disease within the income distribution. For AIDS, prevalence in poor countries is (still) higher among the rich, while for malaria or tuberculosis, prevalence is higher among the poor. In the past, health innovations have often widened health inequalities when first introduced; examples are better sanitation a century or more ago (Preston and Haines 1991); tobacco and lung cancer more recently; and child health improvements in contemporary Brazil (Cesar Victora et al. 2000). Faster transmission of best-practice health care may therefore widen the income distribution within the receiving countries, at least in the first instance.

\section{Empirical Evidence on Inequality and Health}

\subsection{Measuring Income Inequality}

The measurement of income inequality involves conceptual and practical issues. Comprehensive treatments of the theory of inequality measurement were developed in the 1970s by Anthony Atkinson (1970) and Sen (1973), the latter updated in James Foster and Sen (1999). Although there are a number of axioms on the nature of inequality that are broadly accepted, these are in- sufficient to permit us to make unambiguous inequality rankings between any two distributions of income. Instead, the axioms induce a partial ordering whereby we can sometimes rank one distribution as more unequal while, in other cases, we can judge the inequality of distributions only by choosing a specific inequality measure, with different measures giving different results. In particular, different inequality measures give a different emphasis to different parts of the distribution. For example, the gini coefficient is more sensitive to inequality (or to measurement error) at the top of the income distribution, whereas measures that work with the logarithms of income, such as the Theil measures, or the variance of logarithms, are quite sensitive to inequality at the bottom. Although neither the conceptual issues nor the choice of inequality indicator are the most important issues for health, it should be noted that many of the indexes that are used in the public health literature do not satisfy even the generally accepted axioms. For example, the Robin Hood index (more usually known as the relative mean deviation; Kennedy, Kawachi, and Deborah Prothrow-Stith 1996a) is unaffected by transfers between individuals on the same side of the mean. If a transfer program were to transfer incomes from those just below the median to those near the bottom, the Robin Hood index would not change, even though there would have been a real reduction in inequality (and very likely a decrease in mortality risk too.) Perhaps most of the public health work uses as its inequality measure the share of income accruing to the bottom $x$ (often 50) percent of the population. Once again, transfers within the bottom $x$ percent, or within the top $1-x$ percent, will leave the measure unaffected, even though such transfers are capable of having a substantial effect on income inequality more broadly.

Some authors, including Lynch et al. (1998), Luiza Franzini, John Ribble, and William Spears (2001), Paul Brodish, Mark 
Massing, and Herman Tyroler (2000), and Diane McLaughlin and Shannon Stokes (2001) also use the 90:10 ratio defined, not as is usually the case, as the ratio of the 90th to the 10th percentile of the income distribution, but the ratio of the share of income accruing to the bottom 90 percent to the share accruing to the bottom 10 percent. This "inequality" measure has the unfortunate property (for an inequality measure) that it is reduced by transferring income from the middle of the distribution to the top tail; not surprisingly, this measure is sometimes strongly negatively correlated with more usual measures such as the gini; see for example Franzini, Ribble, and Spears. Those authors who use it to demonstrate that inequality affects mortality may well have shown the opposite!

There has also been a good deal of discussion about the appropriate definition of household income, and in particular the treatment of household size. The standard procedure in economics would be to "equivalize" household income by dividing income by some measure of household size, either household size itself, or the number of equivalent adults, for example the number of adults plus half the number of children, or the square root of the total number of people in the household. Such per-equivalent measures attempt to capture the resources available to each person in the household, and recognize that, at the same level of income, members of a larger household are worse off than members of a smaller household. Indeed, public health statisticians, studying pellagra, were among the first to develop equivalent measures; see Edgar Sydenstricker and Willford King (1921). (Even so, it should be noted that there is evidence in Elo and Preston 1996 that, conditional on family income, larger family size may not increase mortality. Nor do equivalized measures give any purchase on whether income is allocated equally within the household) When income inequality is calculated, it is also important that equivalized income be assigned to individuals, and that inequality be calculated over persons, not households. These apparently technical details can sometimes have serious effects on the measurement of income inequality, and their treatment in the public health literature has often been cavalier. There are also obvious constraints when authors restrict themselves to the inequality measures precalculated by the Census Bureau; these restrictions may sometimes be necessary in order to avoid having to deal with other data problems with the public-release micro data.

Conceptual problems are dwarfed by measurement problems. Income itself is hard to measure, and the difficulties multiply when measuring income inequality. Measurement error in income, even if it has little effect on the measurement of mean income, will inflate the measured variance and measured income inequality. The measurement of income is sensitive to survey design, particularly to the choice of the reference periods for income (longer reference periods give lower measured inequality), and to exactly how the income question is asked. The degree of disaggregation of income categories is important, as is whether incomes are reported as a number, or in a set of predefined ranges, typically ending with an open-ended top category. The choice of cutoff points for the ranges is important, particularly the top band which effectively limits the highest income that can be reported. Some surveys permit people to report negative incomes (losses from business activities) and some do not. Some surveys collect data on income, and some on consumption; the latter is almost always less unequally distributed than the formal. The response rate from surveys varies over space and time, and richer households are typically less likely to agree to participate, in many cases because they live in communities where the enumerators cannot reach them; see Robert Groves and Nick Couper (1998). In rich countries, and in some not-so-rich countries, response 
rates have been falling over time, perhaps in response to the increasing competition from market researchers. There are also differences across countries in the degree to which people are prepared to cooperate with government surveys. Response rates in the United States are typically much higher than in Western Europe.

Because different countries use different survey instruments, and have different survey protocols, useful cross-country comparisons of income inequality require detailed knowledge of the specific surveys. Similar issues sometimes arise with comparisons over time within one country, even where the statistical service is of the highest quality. Specifically, the U.S. Census Bureau, in the summer of 2000 , decided that the large increase in household income inequality between 1992 and 1993, which it previously presented as real, was in some unknowable part due to changes in survey methodology, particularly changes in the highest level of income permitted in the questionnaires, as well as the introduction of computer-aided interview technology; see Arthur Jones and Daniel Weinberg (2000). In consequence, the United States no longer has a consistent continuous time series of household income inequality. That the United States is worse (as opposed to more transparent) than other countries seems unlikely.

International data on income inequality come from a number of standard sources. Perhaps the most reliable is the Luxembourg Income Study (LIS) which contains information on the distributions of disposable income for 25 (wealthy) countries over a period of twenty years, although not all countries have data for all years; see Peter Gottschalk and Timothy Smeeding (2000, pp. 273-74). The LIS permits access to the micro data from broadly comparable income data for the covered countries. Note that the underlying surveys do not use the same questionnaire, so that the comparability is not perfect, nor are response rates the same for all countries. Nevertheless, the data are well-documented and have been widely analyzed, so that their properties are well understood. Some authors have taken income inequality data for industrialized countries from other, non-LIS sources, such as Malcolm Sawyer (1976); these are now superceded by the LIS.

Matters are a good deal more difficult for income distribution data from the large numbers of developing countries that are not covered by the LIS. For many years, popular sources of income distribution data were Shail Jain (1975) and Felix Paukert (1973), which are essentially compendia of inequality estimates then available in the World Bank and International Labor Office, respectively. In more recent years, research on international patterns of income inequality has been transformed by the availability on the World Bank web site of the inequality data assembled by Klaus Deininger and Lyn Squire (DS) (1996). These data, which have seen widespread use, contain more than 2,600 observations on gini coefficients (and many quintile shares) for more than 100 developed and developing countries for dates between 1947 and 1994. To be included in the DS data set, estimates have to come from an identifiable source, be national in coverage, and be based on either consumption or income. (Which comes from which is identified.) A subset of the observations are labeled "high-quality" and these have been widely (and mostly uncritically) used in a large number of papers, including papers on income inequality and health. Much of the high-quality data comes from industrialized countries, so that many researchers interested in poor countries have used at least some data not so labeled.

While DS's data and documentation are a great improvement over what was previously available, they do not support the uncritical use that has been made of them, as shown in an important study by Atkinson and Andrea Brandolini (2001). Atkinson and Brandolini focus their attention on the subset of the DS data for the OECD countries, for which 
there are good, well-documented surveys (including the LIS) which can be used for comparison. DS's "high-quality" estimates do not do well in this comparison, either across countries, or in some cases over time within countries. For example, DS shows Sweden as one of the more unequal countries in the OECD, with more income inequality than the United Kingdom, whereas in the LIS (as reported in Gottschalk and Smeeding 2000), Sweden has the lowest income inequality and the United Kingdom the highest apart from the United States. In some cases, such as Germany, the DS time series of inequality is quite different from that computed directly from the surveys. Although the DS data may be more reliable for poor countries than for rich, it is unlikely, especially since the poor countries contain a much larger fraction of the data that are not endorsed by DS themselves.

We are currently in the position of not having any consistently reliable set of data on income inequality outside the countries covered by the LIS. This is in spite of the existence of the fifty or so surveys that have been collected under the aegis of the World Bank's Living Standard Measurement Survey (LSMS), which was set up in 1980 with the original purpose of generating comparable data on income distribution for a wide range of countries. While the LSMS surveys are broadly comparable, the questionnaires are not identical across surveys, and some have differed a great deal.

Research on inequality and health has also used data on measures of inequality for areas within countries. In principle, such measures are less problematic, if only because they are usually calculated from national surveys using a uniform survey instrument so that, even if there are errors, the patterns across areas may not be much affected. One problem is sample size, especially for small areas. Inequality measures are usually less precisely estimated than means so that, for example, the U.S. Bureau of the Census publishes estimates of mean income by state using the Current Population Survey, which has a sample size of around 50,000 households each year. However, it publishes inequality measures by state only for three-year moving averages. Several developing countries also have regular, national household surveys that are large enough to support considerable disaggregation; India, Indonesia, and Pakistan are examples. The Indian National Sample Survey (NSS) collects detailed consumption data from more than 120,000 households every five years or so, and these surveys are designed to be representative for more than seventy regions of the country. Yet even this survey does not support the measurement of income inequality for districts, the level at which the Indian census publishes much of its data on child mortality.

Most household surveys have a two-stage stratified design in which, at the first stage, primary sampling units (PSUs) are randomly selected with probability proportional to population size. These PSUs are typically small geographical units, such as villages or census tracts. Within each PSU, the same number of households are selected so that, over the two stages together, each household in the population has an equal chance of being selected into the survey. In some studies, investigators have calculated measures of local income inequality based on the households in each PSU. This procedure is obviously dangerous when there are only a few households in each PSU and, even when this is not the case, respondents within PSUs are sometimes not randomly selected, so that the relationship between the sample estimate and its population counterpart cannot be assessed. Note too that PSUs are selected for statistical convenience, not analytical meaning, and frequently do not correspond to any sensible definition of a community.

\subsection{Cross-Country Studies of Income Inequality and Health}

Cross-country studies have played an important part in the literature on income 
inequality and health. Preston's (1975) seminal analysis looked at international patterns of GDP and life expectancy, and it was on the basis of his findings that Preston suggested that there should be a negative relationship between income inequality and health. G. B. Rodgers (1979) and A. T. Flegg (1982) were early studies that followed Preston's lead, explicitly looking for (and finding) effects of income inequality on mortality. Rodgers used the Paukert (1973) data for 56 (unnamed) countries and, controlling for income and other variables, found hazardous effects of inequality on lifeexpectancy at birth, life-expectancy at age five, and on the rate of infant mortality, with the last only significant in the developed countries in the sample. Flegg (1982) looked only at child mortality, and found significant effects of income inequality on child mortality in developing countries using the Jain (1975) data. These authors, like Preston, thought of the nonlinearity in the relationship between income and health as the basis for their results, and did not propose any direct effect of income inequality at the microeconomic level. A direct effect was found by Robert Waldmann (1992) who used U.N. and World Bank sources, supplemented by income inequality data from Jain (1975), to investigate infant mortality on a cross section of up to 57 developing and developed countries. As expected, he found that, conditional on mean income, the share of income going to the poorest 20 percent of the population decreased infant mortality, and more surprisingly, that the share of income going to the top 5 percent increased infant mortality. This is a direct effect of inequality; the infant mortality rates among the poor increase when the rich get richer, even when their own incomes do not suffer.

Perhaps the single most cited finding in the literature is Wilkinson's (1992, 1994, 1996) demonstration of a relationship between income inequality and life expectancy across a number of industrialized countries, not only in levels but, more impressively, in changes over time. Countries, such as France and Greece, that narrowed their income distributions by reducing relative poverty, increased their life-expectancies, while those, such as the United Kingdom and Ireland, whose income distributions widened, fell behind (Wilkinson 1996, figure 5.4). Wilkinson interprets these results as showing that, as countries become wealthier and move through the epidemiological transition, the leading cause of differences in mortality moves from material deprivation to social disadvantage. Material deprivation provokes poverty and infectious disease, while social disadvantage provokes stress and chronic disease.

Later research has cast considerable doubt on the robustness and reliability of many of these findings. As expected, one of the main difficulties lies in the unreliability of the data on income inequality. For example, using the Deininger and Squire data, Gravelle, John Wildman, and Matthew Sutton (2002) fail to replicate Rodgers (1979) results for developed and developing countries. Jeffrey Mellor and Jennifer Milyo (2001) use a sample of 47 developing and developed countries in 1990 and find that the positive correlation between the gini coefficient and infant mortality vanishes once secondary school enrolment is controlled for, while the negative correlation between income inequality and life expectancy is eliminated by controlling for income per head. (Commenting on Mellor and Milyo, Kawachi and Tony Blakely 2001 argue that poor education may be a consequence of high income inequality, and it is therefore invalid to include it as a control.) Mellor and Milyo also fail to replicate Wilkinson's results for developed economies. Although the DS data have their own problems, the original results are clearly not robust; see also Lynch et al. (2001) who use the LIS data to demonstrate how the choice of "sample" points (i.e. countries) affects the link between income inequality and adult mortality. The same is true of Waldmann's findings; 
Andrew Baumbusch (1995) replicated Waldmann's analysis using data of the same vintage, but found that income accruing to the top 5 percent reduced infant mortality once the data were updated from the 1993 edition of the World Bank's World Development Report.

The single most convincing study of the LIS countries is by Judge, Jo-Ann Mulligan, and Benzeval (1997), who emphasize the poor quality of the data in previous work, and use the LIS data in their own examination of life expectancy and infant mortality in Australia, Belgium, Canada, Finland, France, Germany, Ireland, Italy, Luxembourg, The Netherlands, Norway, Sweden, Switzerland, the United Kingdom, and the United States. In these data, which are the best international data currently available, the correlation between the gini coefficient and life expectancy is -0.17 , insignificantly different from zero, and neither the gini nor other measures of income inequality are close to significance in any of the regressions explaining life expectancy. The situation is somewhat different for infant mortality rates, where there is a significant positive (i.e. harmful) effect of the ratio of the 90th to the 10th percentile. This measure of inequality exerts a significant effect in several of the regressions, though it becomes insignificant when controls are added for the negative effects on mortality of female labor force participation, see also Lynch et al. (2001) for a similar finding. In these data, the raw correlation between infant mortality and inequality is driven largely by the United States, which is very unequal and has relatively high infant mortality. Inequality in the United States may indeed have something to do with its high infant mortality rate; however, as I shall argue below, any satisfactory discussion of income inequality and mortality in the United States must take explicit account of the effects of race.

If these results are not entirely definitive, it is because the LIS data, although better than any other, are neither fully comparable nor fully accurate. The debate between Wilkinson (1998) and Judge, Mulligan, and Benzeval (1998) has focused on differences in response rates across the LIS surveys, and their possible effect on the results. It is also possible that, as with the difference between infant mortality and life-expectancy, there will be links between specific causes at specific ages and the plausibly associated measures of inequality, see for example Sandra McIsaac and Wilkinson (1997). Yet, it is surely time to agree that there is currently no evidence that income inequality drives life expectancy and all-cause adult mortality within the industrialized countries. It remains to be seen whether this means there is no relationship, or whether there is a relationship that is being obscured by still inadequate data. Judgement on that depends a good deal on whether there exists a relationship between income inequality and health in other contexts, on which more below.

That, conditional on income, there should be a cross-country relationship between infant mortality and income inequality, at least in poor countries and possibly in rich countries, is both theoretically plausible, and rather better supported by the (admittedly inadequate) data that are available. The plausibility comes from recent work from the World Bank which, following the methodology pioneered by Deon Filmer and Lant Pritchett (1999b), has used demographic and health surveys around the world to construct a synthetic measure of wealth, which is then used to explain infant mortality rates; see Davidson Gwatkin (2000) for an overview. The measure of wealth is an index based on the ownership of various durable goods, and while the measure is undoubtedly correlated both with actual wealth and income, we have no way of calibrating the transformation and thus of using the results to relate income to child health. (The transformation is also different in different countries, which effectively precludes meaningful cross-country comparisons.) Nevertheless, the results show very strong 
gradients in child health, with infant mortality rates heavily concentrated at the bottom of the distribution. Wagstaff (2000) uses nine (mostly) LSMS surveys from developing countries to calculate child mortality rates by quintile of equivalent consumption, and shows that child and infant mortality rates typically decline most rapidly between the bottom and second quintile. Whether these results imply that infant mortality rates are convex in income depends on the degree of convexity of the relationship between income and the asset index, and on the density function of equivalent consumption, but that infant mortality is concentrated at the bottom of the income distribution seems likely. Yet there is also some evidence on the other side. In particular, Mamta Murthi, AnneCatherine Guio, and Jean Drèze (1995) find very little effect of poverty on child mortality across districts in India once they control for other factors, most importantly female literacy and urbanization.

To the extent that the DS data are accepted, there is a good deal of empirical evidence from developing countries linking infant and child mortality to the DS measures of income inequality conditional on the level of GDP per head and a range of other variables (for example in Pritchett and Lawrence Summers 1996; Filmer and Pritchett 1999a; and Simon Hales et al. 1999). Whether this evidence extends to adult mortality and life expectancy is difficult to know, not only because of the data difficulties with income inequality, but because of the quality of the data on adult mortality. Few poor countries have complete registration systems for deaths, so that good evidence on adult mortality (or life expectancy at age five, for example) is hard to come by. In a few cases, such as India, there are sample registration surveys, and some data on adult deaths can be gleaned from the demographic and health surveys. But for many countries, data on life expectancy are extrapolated from the data on infant mortality rates, and contain little additional infor- mation. An exception to this generalization comes from the countries of Eastern Europe and the former Soviet Union, where life expectancy has been falling as income inequality has increased (see Marmot and Martin Bobak 2000, fig. 3, which shows a twelvecountry correlation coefficient of -0.63). Peter Walberg et al. (1998) also show that life-expectancy fell fastest in the initially most unequal regions of Russia, a finding that is not obviously related to the inequality hypothesis. Furthermore, as is widely recognized, the Eastern European experience is difficult to interpret because so much else has been going on, so that it is hard to isolate the effect of income inequality.

Finally, there are a number of cross-country studies that link other health outcomes to income inequality. Steckel (1995) finds a relationship between human stature (a measure of cumulative nutritional status) and income inequality on a sample of developed and developing countries using the income distribution from Jain (1975). Mead Over (1998) looks across cities in the developing world and finds that the U.S. Census Bureau's estimates of HIV infection rates are positively related to the DS measures of countrywide income inequality. He interprets his findings in terms of upper income men demanding the services supplied by lower income women, and these results perhaps come closest to providing substance to Paul Farmer's (1999) contention that disease occurs along the "fault lines" in the income distribution. Marie Gaarder (2001) argues that income inequality is likely to worsen the health consequences of pollution because the poor have lower baseline health and are therefore more susceptible. She includes the gini coefficient in a meta-analysis of previous estimated effects of particulate concentration on mortality at various sites around the world and finds significant positive effects. Pablo Fajnzylber, Daniel Lederman, and Norman Loayza (2000) find a significant relationship between DS gini coefficients and both homicide and robbery 
rates for a group of 45 (for homicides) and 34 (for robberies) developed and developing countries. A good deal of this is driven by Latin American countries, where both crime and inequality are very high. Using data on seventeen countries in the Americas, and gini coefficients from DS, Oscar Mujica et al. (2000) confirm the positive correlation $(0.55)$ between homicide and income inequality, but find a negative correlation $(-0.78)$ between suicide rates and income inequality.

\subsection{Within-Country Area Studies of Income Inequality and Health}

As skepticism has grown about the international relationship between income inequality and health, attention has switched to studies within countries, particularly of mortality and income inequality across the states of the United States. Two studies, by George Kaplan et al (1996), and by Kennedy, Kawachi, and Prothrow-Stith (1996a,b), both published in the British Medical Journal, and inspired by Wilkinson's (1992) cross-country work, found a relationship across the states between various measures of income inequality and age-adjusted all-cause mortality, as well as a number of other measures, including infant mortality rates, deaths from cancer, coronary heart disease, and homicide, as well as disability, low birth weight, and crime. Kawachi and Kennedy (1997) established that the results were robust to the choice of inequality indicator, while Lynch et al. (1998) extended the results to 282 metropolitan statistical areas (MSAs) in 1990, finding that the loss of life from income inequality "is comparable to the combined loss of life from lung cancer, diabetes, motor vehicle crashes, HIV infection, suicide, and homicide in 1995." Kawachi, Kennedy, and Prothrow-Stith (1997) argue that income inequality works by reducing social capital, in particular the degree of trust between people, a state-level measure of which is constructed from the General
Social Survey. Such an account is very much in the spirit of stories of psychosocial stress within unequal social structures. In support of this explanation, Wolfson et al. (1999) estimate the degree of nonlinearity in the income to mortality curve using the NLMS (as in figure 2) and show that the effects of income inequality on state mortality rates are too large to be explained by the nonlinearity argument alone, so that there must be some direct effect of income inequality on individual mortality. The implications of these results for economic policy have not gone unnoticed. See for example Kaplan and Lynch's (2001) editorial in the American Journal of Public Health entitled "Is Economic Policy Health Policy?"

These within-nation results do not suffer from the same data problems as do the international comparisons. Income inequality is usually measured from incomes collected in the census, which is administered in the same form to all households in all states. Nor is there any question about the existence of the correlation. Figure 6 shows a typical scatter plot between the log odds of age-adjusted mortality (the log of the ratio of the fraction dying to the fraction not dying) on the vertical axis, and the gini coefficient of household income per equivalent, with equivalents defined as 1 for adults and 0.5 for children aged eighteen and less. The District of Columbia is included and, although it is an outlier in the sense of having higher income inequality and higher mortality than any state, it lies along the regression line defined by the other observations. Across the states of the United States, income inequality is strongly negatively correlated with income; poor states, many of which are in the South, also have the weakest safety nets for the poor. Even so, the correlation between income and mortality is much weaker than the correlation between income inequality and mortality, and adding income to a regression does not eliminate the effect of income inequality. 


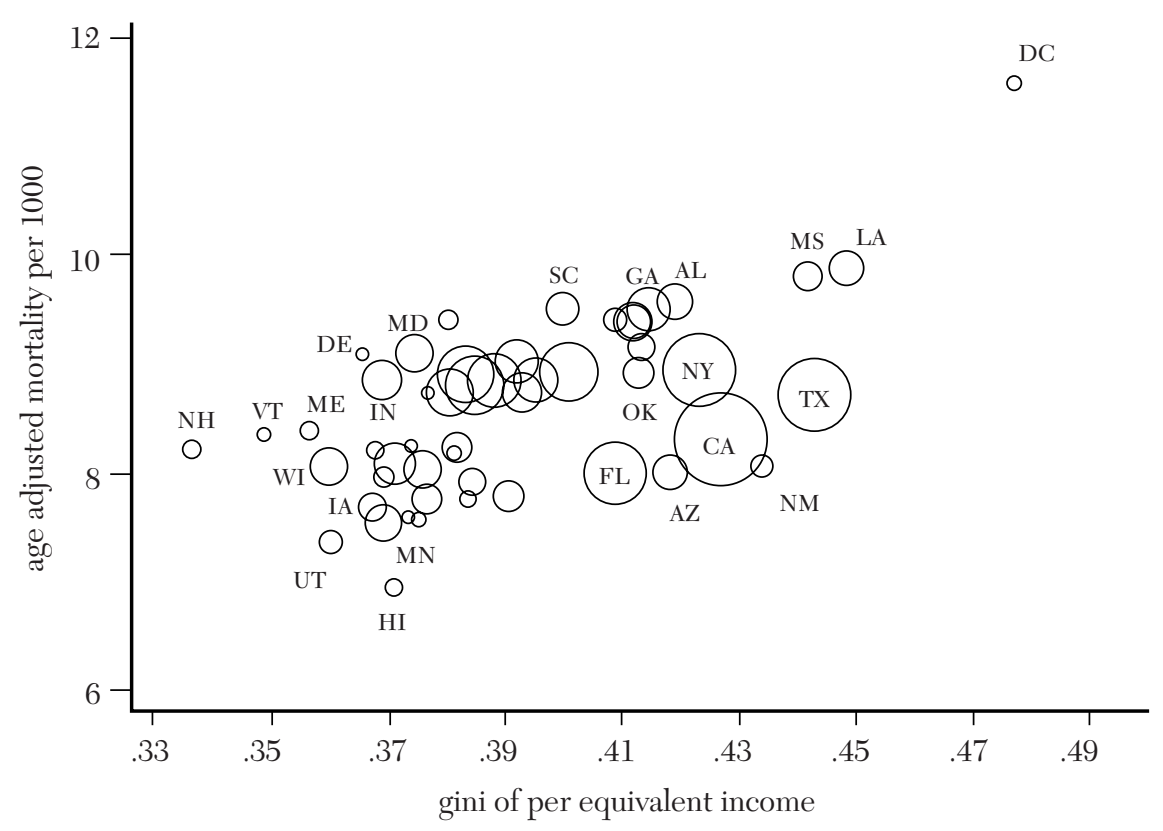

Figure 6. Income Inequality and Age-Adjusted Mortality, U.S. States, 1990

Source: CDC for state (all race, both sex) mortality data, author's calculations from 1990 census for income inequality.

Note: Circles are proportional to population size.

Nevertheless, there are serious questions about whether the correlation between income inequality and mortality is robust through time, and whether it comes from the effects of income inequality or some other factor that is correlated with it. Mellor and Milyo (2001) use data for the 48 continental states from five census years-1950, 1960, 1970, 1980, and 1990 — and reproduce the strong hazardous effect of the gini coefficient on all-cause mortality when only year dummies, the age composition of the state, and median income are included as controls. The inclusion of controls for the average level of education in each state eliminates the significance of the gini coefficient and, once the authors include controls for the fractions of people in each state who are urbanized and who are black, the gini coefficient attracts a negative sign, though one that is not significantly different from zero.
Similar reversals are found for the fraction of births that are low birth weight while, over the five decades, there is no relationship across states between deaths from cardiovascular disease, from malignant neoplasms, or from liver disease. Indeed, for the first two, income inequality has a negative and significant relationship with deaths once controls are entered for income, education, race, and urbanization. Only for homicides and, to a lesser extent, infant mortality and deaths from accidents, is the gini coefficient a risk factor conditional on the other controls. Mellor and Milyo also subject the hypothesis to a much more stringent test, looking at the relationship between ten- and twenty-year changes in mortality and the corresponding changes in income inequality. This is almost certainly too severe a test because it places a great deal of weight on the timing of the link between income inequality 
and mortality. Even so, it is worth noting that, with one exception, none of the income inequality to mortality relationships survives the test. The exception is homicide, where the relationship with income inequality is well-determined and holds over time as well as in the cross-section.

Another concern is the pooling of data across racial or ethnic groups with different incomes and different mortality rates. In the United States, African Americans have higher mortality rates and lower incomes than whites, so that states with a high fraction of blacks tend to have higher mortality rates as well as higher income inequality. As can be seen from figure 6 , such states tend to be predominately in the South where many other special factors are likely to operate; by contrast, the states with low mortality are states where there are few or no African Americans. If data are pooled for 1980 and 1990, the log odds of age-adjusted mortality responds to the gini coefficient with a coefficient of 1.7 for males, and 1.1 for females. In the same regression, the coefficient on the mean of the logarithm of equivalized income is negative for men, but barely significant, and not at all for women (Deaton 2001b). To illustrate the size of the effect of inequality, the 1990 gini coefficients for Louisiana and New Hampshire were 0.45 and 0.33 respectively, which would account for a 12-percent difference in mortality rates, more than half of the difference shown in figure 6 .

If we now confine the calculations to white mortality alone, so that we no longer have the mechanical effects described above, the coefficient on the gini drops to 1.1 for men and to 0.6 for women, about a third lower than for all-race mortality. Nevertheless, these effects remain significantly different from zero, and still show that inequality is a health hazard for the white population alone. If we recalculate the gini coefficients so as to measure only inequality among whites, the effects are further reduced, to 0.6 for men, and 0.4 for women, and only the former is (marginally) significantly different from zero. This result means that the effect of inequality on whites comes, not from the inequality of white incomes, but from the inequality between whites and blacks, raising the suspicion that the effect has more to do with race than with income inequality. Such a suspicion is borne out by controlling for the fraction of the population that is black in each state. It turns out that a high fraction of blacks raises mortality rates among both males and females (note that these are whites) and that conditional on race, income inequality has no effect on mortality. It is unclear why the fraction black should exert such a strong effect on white mortality (black mortality is also higher in states where there are relatively many blacks), though it might be argued that the fraction black is itself some sort of marker for the inequality that characterizes race relations in the United States. Even so, the effect is not one that works through income inequality; once the fraction black is included in the regression, the gini coefficient has no effect.

There is an obvious concern here that I have simply replaced one invalid variableincome inequality - with another-racial composition - and that both stand proxy for something else. This is particularly the case with the state data, where there are at most 51 observations (or 102 observations if we pool data from 1980 and 1990), and where it would be easy to confound racial composition (or income inequality) with geographical factors, especially given the peculiar role of the South. Nevertheless, Deaton and Lubotsky (2003) show that the results carry through to the 287 MSAs that can be consistently identified between 1980 and 1990 . These data can be used to replicate the findings of Lynch et al. (1998), and to show that, once again, the inclusion of racial composition eliminates (and sometimes even reverses) the effect of income inequality. And because there are more MSAs than states, it is possible to work within regions, and to show that whether we look at cities in the 
South, or cities in other regions, and conditioning on city average income, white mortality is higher in cities where the fraction of blacks is higher. The results also holds across nearly all age and sex groups. In apparent contradiction to these results, McLaughlin and Stokes (2002) find that, with county data, controlling for race does not eliminate the effects of income inequality on mortality. Perhaps these findings come from the unfortunate choice of inequality measure (the ratio of the share of the bottom 90 percent to the bottom 10 percent-see above); Deaton and Lubotsky's findings are replicated on the county data.

That the fraction black eliminates the effects of income inequality or mortality is easy enough to understand mechanically; blacks are poorer and whites richer in cities with a large fraction black, so that income inequality is higher where the fraction black is higher, but it is the fraction black, not income inequality, that matters for both white and black mortality. But the finding tells us nothing about what it is about largely black cities that makes them less healthy. One argument is similar to the case against income inequality, that racism generates stress and lack of social capital, sickening both the perpetrators and the victims. But there are other more mundane stories. While there is considerable evidence that the quality of health care is lower for African Americans than for whites (Brian Smedley, Adrienne Stith, and Alan Nelson 2002), there is much less evidence that treatment is different between blacks and whites within the same treatment area, technically within a hospital referral region (Amitabh Chandra and Jonathan Skinner 2002). There is also evidence in Fuchs, Mark McClellan, and Skinner (2002) that the association between the fraction black and white mortality among the elderly is strongest for cardiovascular disease. So one possibility is that, in areas where African Americans make up a large fraction of the population, hospitals are less well-funded or otherwise of lower qual- ity and that, in those areas, both blacks and whites have higher mortality rates. In the event of an acute myocardial infarction (heart attack), people are taken to the nearest facility whatever their income, health insurance status, or race, so that whites, like blacks, will receive the health care provided in their community. As a result, both blacks and whites suffer from the lower-quality health care provided to blacks. Furthermore, in the many metropolitan areas that have multiple hospital referral regions, the effects of the fraction black on white mortality will be attenuated, and on black mortality exaggerated by residential segregation. Segregation effectively transfers the burden of poor treatment from whites to blacks; see Douglas Massey (1991) for this argument in a more general context.

If the apparent effects of inequality or mortality are nothing to do with income inequality per se, but are instead tied to race in America, then there should be no relationship between income inequality and mortality across regions in countries where race does not have the same salience. This seems to be the case. Nancy Ross et al. (2000) find that there is no relation between income inequality and mortality for the ten provinces and 53 metropolitan areas of Canada, and Ross has similar, unpublished findings for Australia. For Britain, there appears to be no area study on income inequality and health, though Yoav Ben-Shlomo, Ian White, and Marmot (1996) find that mortality in the 8,464 wards of England is affected not only by an index of deprivation based on household characteristics, but also by the within-area dispersion of the deprivation index. Again, this is what is to be expected if the deprivation measure is more closely linked to mortality among highdeprivation people. Likewise, Debbie Stanistreet, Alex Scott-Samuel, and Mark Bellis (1999) find a link between mortality and imputed income and income inequality across 366 English local authorities. But their income measures are imputed from 
the occupational structure of each area, assuming that wage rates are identical everywhere, so that they are measures of local occupational patterns, not of income nor income inequality.

Tung-liang Chiang (1999) looks at mortality rates in the 21 counties and cities of Taiwan in 1976, 1985, and 1995 using household survey data to calculate measures of income and income inequality. He finds strong protective effects of income in 1976 and 1985, and little effect of income inequality, but finds that the situation is reversed in 1995, at which date income inequality is a hazard, and income has no effect. Chiang interprets his findings as support for Wilkinson's idea that income is important at low levels of income, and income inequality at high levels of income, which, as we have seen, is also consistent with a nonlinear effect of income and no direct influence of inequality. Enrique Regidor et al. (1997) find no relationship between (a nonstandard) measure of income inequality and the prevalence of long-term disability across the seventeen regions of Spain.

It is widely believed that there is a link between income inequality and crime (including homicide) in the United States. I have already noted Mellor and Milyo's (2001) finding that homicide was the only negative health outcome that was robustly linked to income inequality in their tests, and such findings have consistently appeared in the literature since Isaac Ehrlich (1973); see C. C. Hsieh and M. D. Pugh (1992) for an oft-quoted review and meta-analysis.

There appear to be few relevant studies from developing countries, even where it would be possible to do so, for example in the work on fertility and child mortality in India by Murthi, Guio, and Drèze (1995) and Drèze and Murthi (2001). However, Drèze and Reetika Khera (2000) find that homicide rates across India are unrelated to measures of consumption inequality, but are positively associated with the fraction of "missing" women. Although the authors do not make the point, a link between homicide among men and the shortage of women invites a socio-biological explanation in terms of mating behavior. Rodolfo Peña, Stig Wall, and Lars-Åke Persson (2000) find that infant mortality risks are higher among the poor in Nicaragua, and higher still when the poor live in relatively wealthy neighborhoods, which is consistent with a negative role for inequality.

That there is no interregional relationship between income inequality and mortality is somewhat surprising, given the nonlinear relationships between income and health with which I began. Perhaps the curvature is too mild to generate any strong relationshipand Wolfson et al. (1999) provide such evidence-or perhaps income is not causal. I have already referred to the regional estimates for the United States where education drives out education from aggregated mortality relationships. Another place to look is the time-series data and the patterns of income, income inequality, and mortality over time, and I shall examine that evidence in section 3.5 below.

\subsection{Studies of Income Inequality and Health Using Individual Data}

Studies using individual-level data face different data problems from either the national or the area studies. They have the advantage of being able to look for a direct effect of income inequality without having to allow for the effects of inequality that work through aggregation. But there are compensating difficulties. Because mortality is a rare event, large sample sizes (or long followups) are required to give enough deaths to estimate mortality rates reliably. At the same time, those few health-related surveys that follow people from interview to death are typically very poorly endowed with economic information, including incomes. Nevertheless, there are several surveys in the United States that have been used to look at the determinants of mortality at the individual level. The National Longitudinal 
Mortality Study starts from data collected in the Current Population Survey, mostly around 1980, and then uses the National Death Index to check whether members of responding households are dead by each follow-up date. Currently, around 1.3 million people have been tracked for up to a decade. In principle, the CPS provides excellent and detailed economic information, but many of the rounds used for the NLMS were not the March surveys, when income data are collected, and so contain only rudimentary information on household incomes.

There are two other U.S. health surveys with later merges of death-certificate data: the National Health Interview Survey (NHIS), which interviews around 50,000 households every year, and the National Health and Nutritional Examination Survey (NHANES) the first round of which surveyed more than 14,000 people between 1971 and 1975, for whom information on deaths has been merged up to 1987. A final source of mortality data is the Panel Study of Income Dynamics (PSID), which has followed around 5,000 households (and their children and split-offs) since 1968. Because this is a panel survey returning regularly to each household, deaths are reported by surviving family members. All four of these surveys have been used to look at the relationship between mortality, income, and income inequality.

Sweden also has nationally representative data that works in the same way as the NLMS in the United States, though with even more comprehensive data. Since 1975, Statistics Sweden has interviewed around 7,000 individuals each year in its Survey of Living Conditions, and these people have been linked, not only to the national death statistics, but to income information from the national income tax statistics; see Ulf Gerdtham and Magnus Johannesson (2001).

A second line of work has used, not mortality, but self-reported measures of overall health status. The questions are included in a large number of surveys, if only because they are asked easily and quickly. They ask respondents to rate their health on a fivepoint scale from "poor," to "fair," to "good" to "very good" and "excellent." Many investigators convert this to a binary indicator of poor health, corresponding to the "poor" and "fair" categories; such an indicator has been validated as a powerful predictor of subsequent morbidity and mortality, even conditional on a physician's examination; (Ellen Idler and Yeal Benyamini 1997). Even so, there is no automatic link between morbidity and mortality; indeed there are reasons why they might move in opposite directions; see Christopher Murray (1996) for a good discussion. Self-reported general health questions are included in the NHIS, in the Behavioral and Risk Factor Surveillance Study (BRFSS) and, from 1995 onwards, in the Current Population Survey.

The interpretation of the individual studies, and of the extent to which they support a link from inequality to health depends a great deal on who is doing the interpreting. Nevertheless, there is general agreement that the results from these studies are weaker and more ambiguous than the area studies. For example, Kimberley Lochner et al. (2001), using the NHIS and merged mortality data, find only a small effect of state income inequality on mortality (relative risk of living in the top five most unequal states compared with the ten most equal states of 1.12). This effect, which is estimated with controls for family income and the statelevel poverty rate, is only statistically significant for near-poor whites. Kevin Fiscella and Peter Franks (1997) find that, once they control for individual income, there is no effect of PSU-level inequality on the probability of dying in the NHANES follow-up, but there are real questions about whether their measure of inequality - the share of income accruing to the bottom 50 percent of the population - can be adequately measured from the PSU data in the NHANES itself, within which respondents are not randomly drawn. Mary Daly et al. (1998) find no effect 
of state-level income inequality on individual five-year mortality rates using data from the PSID. As I shall explain in more detail below, state-level income inequality also has no detectable effect on individual mortality in the NLMS.

Several studies find a range of results, with at least some studies finding an effect of income inequality on self-reported morbidity. See Mah-Jabeen Soobader and Felicia LeClere (1999, using the NHIS with merged census county-level inequality data), Kennedy et al. (1998, using the BRFSS merged with state-level inequality data), Fiscella and Franks (2000, using the NHIS), Mellor and Milyo (2002) and Blakely, Lochner, and Kawachi (2002) using the CPS with inequality data from the CPS at various geographical levels; and Roland Sturm and Carole Roan Gresenz (2002) and Robert Kahn et al. (2000) using other health surveys. The estimated effects are typically modest, and in several cases are eliminated when controls are added for individual income. For example, Mellor and Milyo show that their effects are removed once controls are introduced for income and its square, as well as for fixed state effects. (Note again that this last is a severe test; Mellor and Milyo only have three years of CPS data, so they are effectively demanding a link between changes in morbidity and changes in income distribution between 1995 and 1997). But LeClere and Soobader (2001) also demonstrate considerable fragility in the results, showing that the effects seem to work only for whites aged 18-44 in highinequality counties, and middle-aged whites in very-high-inequality counties. There are no effects for other whites, nor for nonHispanic blacks. Blakely, Lochner, and Kawachi (2002) is the most recent and one of the most careful studies; it concludes that, after controlling for income, and apart from the possible effects of income inequality that work through aggregation, there is little association between income inequality and being in poor health in the CPS data from 1996 and 1998. This conclusion is echoed for Japan, where the raw correlation between poor health and the prefecture gini coefficient is eliminated once individual income is controlled for (Kenji Shibuya, Hideki Hashimoto, and Eiji Yano 2002).

As noted, Wolfson et al. (1999) show that the degree of curvature in the NLMS (figure 2) is insufficient to explain the large effects of income inequality on mortality at the state level. In Deaton (2001b), I address more directly the role of state income inequality on mortality in the NLMS. The NLMS distinguishes seven income groups, so that at the first stage of the analysis, I use a logit model to estimate the log odds of dying during the ten-year follow up as a linear function of age including dummy variables for each of the seven income groups. These logits are estimated for white males and females separately, using data only for those aged 18 to 75 at the time of first interview. (The log odds of mortality is approximately linear in age over this range.) In order to conduct a state-level analysis, each of these models is fitted to data for a single state, thus allowing inequality-or any other state-level effect-an unrestricted effect on the relationship between mortality and income. The first stage produces numbers for each state like the points shown as circles in figure 1 , so that, at the second stage, it is possible to examine whether these points are higher in states where income inequality is higher. Note that this two-stage procedure is as general as a single-stage model in which individual mortality is linked to state-level data on income inequality.

My original concern was to test the model of relative deprivation presented in section 2.2.5 above. This was done by comparing the effects of each income group in each state with the predicted values from computing relative deprivation. While states are by no stretch of the imagination plausible reference groups, it is at the state level that the inequality effects were first discovered, so it 
is tempting to try to account for the effect using the relative deprivation story. Within states, the relative deprivation story does well, outperforming a simple model in which income itself accounts for the differences across income groups; Eibner (2000) finds similar results using a range of definitions for reference groups. However, the relative deprivation model accounts for essentially none of the variation in mortality across states which, given the theory, means that the gini coefficient does not predict interstate mortality differences in the NLMS data. This finding is supported (even without controls for income) using the $1.3 \mathrm{mil}-$ lion observations in the full NLMS. Table 13 in Rogot et al. (1992) shows no correlation across the states between age-adjusted mortality and income inequality, a finding that is in direct contradiction with figure 6 and with the findings listed at the outset of section 3.4 above. This contradiction is resolved (at least in part) by the demonstration that, in these individual-level data as in the aggregate state-level data, the fraction black in each state is a powerful predictor of white mortality.

Once again, there is no direct effect of income inequality. Because the racial composition of areas is such a strong predictor of mortality in the aggregate state, MSA, and county-level data, as well as in the individual data from the NLMS, it would be interesting to discover whether the Lochner et al. (2001) findings on mortality in the NHIS follow-up can also be attributed to racial composition; given their partition of states into inequality groups, it seems likely.

Taking income and mortality together, the Swedish data used by Gerdtham and Johanesson (2001) are probably of higher quality than anything currently available in the United States. Gerdtham and Johanesson used the 284 municipalities of Sweden as their communities, and examine individual mortality for 41,006 individuals aged between 20 and 84 who were interviewed between 1980 and 1986 and whose mortality was followed until the end of 1996. Mortality was assessed relative to individual income, community income, and community income inequality, with the latter two measured from the survey data itself, a procedure subject to the reservations raised above. As in all similar studies, individual income was strongly protective, even allowing for education and a host of other variables, including initial health status, but neither inequality nor mean community income appeared to have any effect. The last result is evidence against the relative income hypothesis so that, once again, we are led back to the original model in which health is an increasing nonlinear function of absolute income. Finally, in another impressive Nordic study, Merete Osler et al. (2002) use data on nearly 26,000 people from Copenhagen who were followed for an average of 12.8 years. These survey data, which include data on behavioral risk patterns, were merged with administrative data on housing, income, education, and occupation, as well as income equality (share accruing to the bottom 50 percent) at the parish level, calculated from population, not survey, data. Without controls, income inequality is positively related to mortality, but the effect is eliminated by adding the other variables; indeed, adding individual income is sufficient to eliminate the effect of inequality on mortality.

\subsection{Inequality and Mortality Decline in the United States and Britain}

A final source of evidence comes from examining whether there is a link between mortality and the increase in income inequality in the 1980s in both Britain and the United States. Wilkinson (1996) argues that for Britain, mortality rates for infants and for young adults fell less rapidly after 1985 than would have been the case had income inequality remained constant. Wilkinson (1996, figure 5.10, p. 97) plots a time series of mortality, not only of infants, but also of children and young adults, and shows that the sum of age-adjusted mortality rates fell 
less rapidly after 1985 than it did in the decade from 1975 to 1985 . These findings, together with the corresponding evidence for the United States were recently examined in Deaton and Paxson (2001b). Their results are as follows.

There were large increases in income inequality in both Britain and the United States in the 1970s and 1980s. In both countries, inequality in family and household income increased from the early or mid-1970s until around 1990, with (arguably) little increase but certainly no decline since. By the early to mid-1980s, inequality had risen to new postwar highs and continued to increase, at least until 1990. As pointed out by Wilkinson, the rate of decline of infant mortality was particularly rapid in the decade from 1975 to 1985 , and less rapid thereafter. The same is true in the United States, though the period of rapid decline starts somewhat earlier, in the late 1960s, and finishes earlier, around 1980. In both countries, the rate of decline of mortality rates among young adults has slowed steadily, and by 1985 mortality rates are either flat or actually rising. For infants and young adults taken together, the rate of mortality decline has therefore been a good deal slower in recent years than in the period before the increase in income inequality.

Even so, it is unlikely that income inequality has much to do with these mortality trends. First, the episodes of rapid decline in the infant mortality rate are episodes, not trends. Prior to the periods of rapid decline in each country, progress was slower, with a rate of decline comparable to that after the end of the episode. Yet income inequality was not high prior to the onset of the rapid decline, so that in neither country since 1950 has there been a consistent relationship between income inequality and the rate of decline of infant mortality. Second, we know a good deal about the causes of the decline in infant mortality, much of which can be attributed to declines in perinatal mortality through new techniques for preventing the deaths of low birth-weight babies. These techniques diffused more quickly in the United States than in the United Kingdom, so that the rapid decline in mortality started first in the United States, and its possibilities were more rapidly exhausted there. There seems no reason other than coincidence to link the timing of this exhaustion to the rise in income inequality. Third, among young adults, much of the increase in mortality is attributable to HIV/AIDS, for which the rise in income inequality in the mid-1980s is not the cause. Finally, if we look at mortality rates of adults aged 45 and above, there is a period of unusually rapid mortality decline (particularly although not exclusively for men) that began around 1970 (again a little earlier in the United States), and continues to the present. So if income inequality is hazardous for the young, it is protective for their elders! Once again, a more convincing explanation lies in the increased use, first in the United States and later in Britain, of lifesaving technologies for dealing with cardiovascular disease, angioplasty, coronary artery bypass grafts, and the use of clot-busting drugs and even aspirin.

The time-series results also cast doubt on the role of income in promoting health. For most age groups, the rate of mortality decline was slow during the period of rapid growth in median incomes from 1950 until the early 1970s, and much more rapid thereafter during the period of the productivity slowdown. In Britain, there is no slowdown in the rate of growth of real disposable personal incomes after the mid-1970s, so that the pattern of income growth was very different from that in the United States. Yet the patterns of mortality decline were very similar. Neither income nor income inequality help us explain British and American mortality patterns in the two quarter centuries after 1950 .

\section{Summary and Conclusions}

The stories about income inequality affecting health are stronger than the evidence. 
Judging by the explosion of interest and of citations, there is a strong appeal to the idea that before the epidemiological transition, income determines mortality, while after it, income inequality determines mortality; that in poor countries, income protects against poor sanitation, unhealthy working and living environments, poor nutrition, and a plethora of infectious diseases; that in rich countries, where these evils are but distant memories, income inequality is an indicator of the quality of social arrangements, of stress, and of mortality. Yet, as we have seen, even if it is true that, at higher income levels, income inequality becomes relatively more important as a cause of death, there is no need to assume that the relationship between income and mortality changes with economic development. If it is poverty, not inequality, that drives mortality, so that income has a much bigger effect on health at low than high incomes, average income will eventually cease to be associated with poor health, while the effects of inequality will endure for much longer because, even in rich economies, there are some who are not so rich. Income inequality will continue to affect mortality until everyone ceases to be poor, which happens long after average income has risen out of the range of poverty.

But it is not true that income inequality itself is a major determinant of population health. There is no robust correlation between life expectancy and income inequality among the rich countries, and the correlation across the states and cities of the United States is almost certainly the result of something that is correlated with income inequality, but that is not income inequality itself. The rapid increases in income inequality in the 1980s have not been associated with any slowdown in the rate of mortality decline. Studies of individual mortality and income inequality show no link, except for one survey where the estimated effects are small and are confined to one population group. Infant and child mortality in developing countries is primarily a consequence of poverty so that, conditional on average income, income inequality is important only because it is effectively a measure of poverty. But it is low incomes that are important, not inequality, and there is no evidence that making the rich richer, however undesirable that may be on other grounds, is hazardous to the health of the poor or their children, provided that their own incomes are maintained. The only exception to these generalizations is perhaps the case of homicide, where income inequality itself appears to play a genuine role.

These conclusions are not different from those of earlier commentators, particularly Judge (1995); Judge, Mulligan, and Benzeval (1997); Wagstaff and Eddy van Doorslaer (1999); and Judge and Iain Patterson (2001). Yet these results must not be misinterpreted. While they do imply that income inequality is not important per se, other than its effects through poverty, they do not imply that the social environment is not important for individual health, let alone that individual health is determined by individual characteristics and the provision of personal medical care. We know from Whitehall and from other studies that positions in hierarchies matter, perhaps through an ability to control one's life, but in any case through some mechanism that works through relationships with other human beings. In the United States in 1999, black males had a life expectancy at birth 6.8 years shorter than white males; for females, the discrepancy was 5.2 years (CDC 2002). There is a twenty-year gap in life expectancy between white men in the healthiest counties and black men in the unhealthiest counties (Murray 1998 quoted by Marmot 2001). Hispanic Americans have longer lifeexpectancies than whites. And there are differences within racial and ethnic groups by education and income. As I have argued above, across cities, states, and counties of the United States, places that have a larger African-American population are unhealthier, with both whites and African Americans 
dying younger than would otherwise be the case. We do not know why this should be the case, whether the nature of race relations in America is so difficult that it is actually a health hazard, or whether what we see is the result of lower-quality health care in places where there are large black populations. If the latter, residential segregation is likely to improve the health of whites at the expense of blacks, and there is some evidence in the literature that, indeed, segregation harms the health of African Americans (Thomas Laveist 1993 and Ingrid Gould Ellen 2000). All of these cases involve inequality of one kind or another, residential or racial, but not income inequality per se.

I have also emphasized several other cases where reductions in deprivation in one dimension - whether it be land ownership (the nutritional wage story), democratic rights (England in the 1870s or the American South in the 1960s), women's agency (health and fertility in India), or income (through malnutrition or freedom from stress)—will bring benefits not only in and of themselves, but also to the relief from other deprivations, in this case particularly the deprivation of ill health. This is of course Sen's (1999) theme in Development and Freedom, that relief from any one of a number of interlinked deprivations, each of which is an important "unfreedom" in its own right, helps promote relief from the others. This is quite different from a story in which income inequality is the principal actor and main villain.

These results are entirely consistent with what is known of about the biology of stress and disease. That rank can be protective of health, including enhancing the resistance to infection, has been demonstrated in both animal and human experiments (Sheldon Cohen 1997, 1999). That repeated stress associated with the insults and lack of control that come from low rank has a well-developed biochemical basis (see for example Robert Sapolsky 1993, and Bruce McEwen 1998). Yet there is nothing that necessarily implicates income, let alone income in- equality, as the main correlate of the degree to which people experience disease-inducing insults. Some of the institutions where rank is likely most protective-prisons or the military - are not characterized by wide income inequality, nor even by important differences in income. Inequality may be important, but there is little that suggests it is income inequality.

My conclusions carry a number of implications for the direction of future research. The most obvious is that attention should be directed away from income inequality per se. Instead, the urgent need is to investigate the role that income plays in promoting healthwhether the effects of income come from income itself, or from correlates such as education, wealth, control, or rank. We need to know why income is so important in the individual level studies, and so apparently unimportant at the aggregate level over space or over time. If income is indeed directly protective, we need to know whether the effect is really nonlinear and by how much, because it is this, and not any direct effect of income inequality on health, that determines whether and by how much income redistribution can improve population health.

\section{REFERENCES}

Adams, Peter; Michael D. Hurd, Daniel McFadden, Angela Merrill and Tiago Ribeiro. 2003. "Healthy, Wealthy, and Wise?" J. Econometrics, 112, pp. 3-56. Aghion, Philippe; Eve Caroli and Cecilia GarcíaPeñalosa. 1999. "Inequality and Economic Growth: The Perspective of the New Growth Theories," J. Econ. Lit. 37:4, pp. 1615-60.

Alesina, Alberto; Reza Baqir and William Easterly. 1999. "Public Goods and Ethnic Divisions," Quart. J. Econ. 114, pp. 1243-84.

Almond, Douglas V.; Kenneth Y. Chay and Michael Greenstone. 2001. "Civil Rights, the War on Poverty, and Black-White Convergence in Infant Mortality in Mississippi,” econ. dept., U. Cal. Berkeley.

Atkinson, Anthony B. 1970. "On the Measurement of Inequality," I. Econ. Theory 2, pp. 244-63.

Atkinson, Anthony B. and Andrea Brandolini. 2001. "Promise and Pitfalls in the Use of 'Secondary' Data Sets: Income Inequality in OECD Countries," J. Econ. Lit. 39, pp. 771-99.

Auster, Richard; Irving Leveson and Deborah Sarachek. 1969. "The Production of Health: An Exploratory Study," J. Human Res. 4, pp. 411-36. 
Backlund, E.; Paul D. Sorlie and Norman J. Johnson. 1999. "A Comparison of the Relationship of Education and Income with Mortality: the National Longitudinal Mortality Study," Soc. Sci. Med.. 49, pp. 1373-84.

Bardhan, Pranab; Samuel Bowles and Herbert Gintis. 2000. "Wealth Inequality, Wealth Constraints, and Economic Performance," in Handbook of Income Distribution. Anthony B. Atkinson and François Bourguignon, eds. Vol. 1, Amsterdam: North-Holland, pp. 541-603.

Barker, David J. P. 1994. Mothers, Babies, and Disease in Later Life. London: BMJ Publishing.

— 1995. "Fetal Origins of Coronary Heart Disease," Brit. Med. J. 311, pp. 117-4.

Baumbusch, Andrew P. 1995. "Income Inequality and Infant Mortality," Princeton U., junior independent work.

Benabou, Roland. 1996. "Inequality and Growth," in NBER Macroeconomics Annual. Ben Bernanke and Julio Rotemberg, eds. Cambridge: MIT Press.

Ben-Shlomo, Yoav; Ian R. White and Michael Marmot. 1996. "Does the Variation in Socio-Economic Characteristics of an Area Affect Mortality?" Brit. Med. J. 312, pp. 1013-14.

Benzeval, Michaela and Ken Judge. 2001. "Income and Health: The Time Dimension," Soc. Sci. Med. 52, pp. 1371-90.

Benzeval, Michaela; Ken Judge and Sue Shouls. 2001. "Understanding the Relationship Between Income and Health: How Much Can Be Gleaned from Cross-Sectional Data?" Soc. Policy Admin. 35, pp. 376-96.

Binswanger, Hans and Mark Rosenzweig. 1984. Contractual Arrangements, Employment, and Wages in Rural South Asia. New Haven: Yale U. Press.

Bliss, Christopher J. and Nicholas H. Stern. 1978. "Productivity, Wages, and Nutrition," J. Devel. Econ. 5, pp. 331-98.

Blakely, Tony A.; Kimberley Lochner and Ichiro Kawachi. 2002. "Metropolitan Area Income Inequality and Self-Rated Health-A Multilevel Study," Soc. Sci. Med. 54, pp. 65-77.

Bowles, Samuel and Herbert Gintis. 1998. "Is Equality Passé?" Boston Rev. 23, pp. 4-35.

Brodish, Paul; Mark Massing and Herman Tyroler. 2000. "Income Inequality and All-Cause Mortality in the 100 Counties of North Carolina," South. Med. J. 93, pp. 386-91

Brunner, Eric and Michael Marmot. 1999. "Social Organization, Stress, and Health," in Social Determinants of Health. Michael Marmot and Richard G. Wilkinson, eds. Oxford: Oxford U. Press.

Card, David and Alan B. Krueger. 1993. "Trends in Relative Black-White Earnings Revisited," Amer. Econ. Rev., Papers and Proceedings 83, pp. 85-91.

Case, Anne. 2001. "Does Money Protect Health Status? Evidence from South African Pensions," NBER work. paper 8496, Cambridge, MA.

- 2002. "Health, Income, and Economic Development," Proceedings of the World Bank Conference on Development Economics, 2001/2002, World Bank, pp. 221-41.
Center for Disease Control. 2002. National Vital Statistics Report, 50:6, March.

Chandra, Amitabh and Jonathan Skinner. 2002. "Geography and Racial Health Disparities," econ. dept., Dartmouth College, processed.

Chattopadhyay, Raghabendra and Esther Duflo. 2001. "Women's Leadership and Policy Decisions: Evidence from a Nationwide Randomized Experiment in India," I.I.M. Calcutta and econ. dept. MIT.

Chiang, Tung-liang. 1999. "Economic Transition and Changing Relation between Income Inequality and Mortality in Taiwan: Regression Analysis," Brit. Med. J. 319, pp. 1162-65.

Cohen, Sheldon; S. Line, S. B. Manuck, B. S. Rabin, E. R. Heise and J. R. Kaplan. "Chronic Social Stress, Social Status, and Susceptibility to Upper Respiratory Infections in Nonhuman Primates," Psychosom. Med. 59:3, pp. 213-21.

Cohen, Sheldon. 1999. "Social Status and Upper Respiratory Infection," in Socioeconomic Status and Health in Industrialized Nations: Social, Psychological, and Biological Pathways. Nancy Adler et al., eds. Annals NY Academy Science 896, pp. 246-53.

Daly, Mary C.; Greg J. Duncan, George A. Kaplan and John W. Lynch. 1998. "Macro to Micro Links in the Relation Between Income Inequality and Mortality," Milbank Quart. 76, pp. 315-39.

Dasgupta, Partha. 1993. An Inquiry into Well-being and Destitution. Oxford: Clarendon Press.

Dasgupta, Partha and Debraj Ray. 1986. "Inequality as a Determinant of Malnutrition and Unemployment: theory," Econ. J. 96, pp. 1011-34.

_. 1987. "Inequality as a Determinant of Malnutrition and Unemployment: Policy," Econ. J. 97, pp. 177-88.

Deaton, Angus. 2001a. "Inequalities in Income and Inequalities in Health," in The Causes and Consequences of Increasing Inequality. Finis Welch, ed. Chicago: U. Chicago Press, pp. 285-313.

_. 2001b. "Relative Deprivation, Inequality, and Mortality," Princeton U. Research Program Development Studies and Center for Health and Wellbeing (NBER work. paper 8099).

. 2002. "Policy Implications of the Gradient of Health and Wealth," Health Affairs 21, pp. 13-30.

Deaton, Angus and Christina Paxson. 2001a. "Mortality, Education, Income, and Inequality among American Cohorts," in Themes in the Economics of Aging. David Wise, ed. Chicago U. Press for NBER (NBER work. paper 7140)

2001b. "Mortality, Income, and Income Inequality among British and American Cohorts," Center for Health and Wellbeing, Princeton U., processed.

Deaton, Angus and Darren Lubotsky. 2003. "Mortality, Inequality and Race in American Cities and States," Soc. Sci. Med., forthcoming.

Deininger, Klaus and Lyn Squire. 1996. "A New Data Set Measuring Income Inequality," World Bank Econ. Rev. 10, pp. 565-91.

Doblhammer, Gabriele. 2002. "Differences in Lifespan by Month of Birth for the United States: The Impact of Early Life Events and Conditions on Late Life Mortality," Max Planck Institute for Demographic Research, work. paper 2002-19. 
Doblhammer, Gabriele and James W. Vaupel. 2001. "Lifespan Depends on Month of Birth," Proceedings Nat. Academy Sci. 98, pp. 2934-9.

Donohue, John J. and James J. Heckman. 1991. "Continuous Versus Episodic Change: The Impact of Affirmative Action and Civil Rights Policy on the Economic Status of Blacks," J. Econ. Lit. 29, pp. $1603-44$.

Drèze, Jean and Reetika Khera. 2000. "Crime, Gender, and Society in India: Insights from Homicide Data," Population Devel. Rev. 26, pp. 335-52.

Drèze, Jean and Mamta Murthi. 2001. "Fertility, Education, and Development: Evidence from India," Population Devel. Rev. 27, pp. 33-63.

Easterlin, Richard A. 1974. "Does Economic Growth Improve the Human Lot? Some Empirical Evidence," in Nations and Households in Economic Growth. P. A. David and W. R. Levin, eds. Stanford: Stanford U. Press, pp. 98-125.

- 1996. Growth Triumphant: the Twenty-first Century in Historical Perspective. Ann Arbor: U. Michigan Press.

Ehrlich, Isaac. 1973. "Participation in Illegitimate Activities: A Theoretical and Empirical Investigation," J. Polit. Econ. 81, pp. 521-65.

Eibner, Christine. 2001. "Relative Deprivation, Poor Health Habits, and Mortality," Princeton, Center for Health and Wellbeing work. Paper, May (http:// www.wws.princeton.edu/ chw/papers.html)

Ellen, Ingrid Gould. 2000. "Is Segregation Bad for Your Health? The Case of Low Birth Weight," Brookings-Wharton Pap. Urban Affairs pp. 203-38.

Elo, Irma and Samuel H. Preston. 1996. "Educational Differentials in Mortality: United States, 1979-85," Soc. Sci. Med.42, pp. 47-57.

Erdal, David, and Andrew Whiten. 1996. "Egalitarianism and Machiavellian Intelligence in Human Evolution," in Modelling the Early Human Mind. Paul Mellars and Kathleen Gibson, eds. McDonald Institute Monographs, pp. 139-50.

Fajnzylber, Pablo; Daniel Lederman and Norman Loayza. 2000. "Crime and Victimization: An Economic Perspective,” Economía 1, pp. 219-78.

Farmer, Paul. 1999. Infections and Inequalities: the modern plagues. Berkeley: U. California Press.

Fehr, Ernst, and Klaus M. Schmidt. 1999. "A Theory of Fairness, Competition, and Cooperation," Quart. J. Econ. 114, pp. 817-68.

Feinstein, Jonathan S. 1993. “The Relationship Between Socioeconomic Status and Health: a review of the literature," Milbank Quart.71, pp. 279-322

Filmer, Deon, and Lant Pritchett. 1999a. "The Impact of Public Spending on health: does money matter?" Soc. Sci. Med. 49, pp. 1309-23.

_. 1999b. "The Effect of Household Wealth on Educational Attainment: evidence from 35 countries," Population Devel. Rev. 25, pp. 85-120.

Fiscella, Kevin, and Peter Franks. 1997. "Poverty or Income Inequality as a Predictor of Mortality: longitudinal cohort study," Brit. Med. J. 314, pp. $1724-28$.

2000. "Individual Income, Income Inequality, Health and Mortality: what are the relationships?" Health Services Res. 35, pp. 307-18.
Flegg, A.T. 1982. "Inequality of Income, Illiteracy and Medical Care as Determinants of Infant Mortality in Developing Countries," Population Stud. 36, pp. 441-58.

Fogel, Robert W. 1994 "Economic Growth, Population Theory and Physiology: the bearing of long-term processes on the making of economic policy," Amer. Econ. Rev. 84, pp. 369-95.

_. 1997. "New Findings on Secular Trends in Nutrition and Mortality: some implications for population theory," in Handbook of Population and Family Economics. Mark Rosenzweig and Oded Stark, eds. Vol 1A, Amsterdam: Elsevier.

Foster, James and Amartya K. Sen. 1997. "On Economic Inequality After a Quarter of a Century,” annex to Sen, Amartya K., On Economic Inequality. Oxford: Clarendon Press.

Fuchs, Victor. 1993. "Poverty and Health: asking the Right Questions," in Medical Care and the Health of the Poor. David E. Rogers and Eli Ginzberg, eds. Boulder: Westview Press.

Fuchs, Victor; Mark McClellan and Jonathan Skinner. 2001. "Area Differences in Utilization of Medical Care and Mortality among U.S. Elderly," NBER work. paper 8628, Cambridge, MA.

Franzini, Luiza; John Ribble and William Spears. 2001. "The Effects of Income Inequality and Income Level on Mortality Vary by Population Size in Texas Counties," J. Health Soc. Behav. 42, pp. 373-87.

Gaarder, Marie M. 2001. "Can Population Characteristics Account for the Variation in Health Impacts of Air Pollution? A Meta Analysis of PM10-Mortality Studies," University College, London, processed.

Garber, Alan M. 1989. "Pursuing the Links between Socioeconomic Status and Health: critique, policy implications, and directions for future research," in Pathways to Health: The Role of Social Factors. John P. Bunker, Deanna S. Gombey and Barbara Kehrer, eds. Menlo Park, CA. Kaiser Family Foundation, pp. 271-315.

Galor, Oded and Omer Moav. 2000. "From Physical to Human Capital Accumulation: inequality in the process of development," econ. dept. Brown U. and MIT, processed.

Gerdtham, Ulf-G. and Magnus Johannesson. 2001. "Absolute Income, Relative Income, Income Inequality and Mortality," Stockholm School Econ., processed.

Gertler, Paul and Jonathan Gruber. 2002. "Insuring Consumption against Illness," Amer. Econ. Rev. 92, pp. $51-70$

Gersovitz, Mark. 1983. "Savings and Nutrition at Low Incomes," J. Polit. Econ. 91, pp. 841-55.

Goldin, Claudia and Lawrence F. Katz. 2001. "Decreasing (and Then Increasing) Inequality in America: A Tale of Two Half-Centuries," in The Causes and Consequences of Increasing Inequality Finis Welch, ed. Chicago: U. Chicago Press, pp. 37-82.

Gottshcalk, Peter and Timothy Smeeding. 2000. "Empirical Evidence on Income Inequality in Industrial Countries," in Handbook of Income Distribution. Anthony B. Atkinson and François Bourguignon, eds. Vol. 1, Amsterdam: North-Holland, pp. 261-307. 
Gravelle, Hugh. 1998. "How Much of the Relation between Population Mortality and Unequal Distribution of Income Is a Statistical Artefact?” Brit. Med. J. 316 , pp. 382-85.

Gravelle, Hugh; John Wildman and Matthew Sutton. 2002. "Income, Income Inequality and Health: What Can We Learn from the Aggregate Data?" Soc. Sci. Med. 54, pp. 577-89.

Grossman, Michael. 1972. "On the Concept of Health Capital and the Demand for Health," J. Polit. Econ. 80 , pp. 223-55.

. 1975. "The Correlation between Health and Schooling," in Household Production and Consumption. Nestor Terleckyj, ed. NY: Columbia U. Press for NBER, pp. 147-211.

— 2000. "The Human Capital Model," in Handbook of Health Economics. Anthony J. Culyer and Joseph P. Newhouse, eds. Vol 1A, Amsterdam: Elsevier, pp. 347-408.

Groves, Robert M. and Mick P. Couper. 1998. Nonresponse in Household Interview Surveys. NY: Wiley.

Gwatkin, Davidson R. 2000. "Health Inequalities and the Health of the Poor: What Do We Know? What Can We Do?” Bull. World Health Org. 78, pp. 3-18.

Haines, Michael R. and Hallie J. Kintner. 2000. "The Mortality Transition in Germany, 1860-1935," Hist. Methods 33, pp. 83-104.

Hales, Simon; Philippa Howden-Chapman, Clare Salmond, Alistair Woodward and Johan Mackenbach. 1999. "National Infant Mortality Rates in Relation to Gross National Product and Distribution of Income," Lancet 354, pp. 2047.

Hammond, Richard J. 1951. Food. History of the Second World War, United Kingdom Civil Series, London, H. M. Stationery Office.

Hsieh, C. C. and M. D. Pugh. 1993. "Poverty, Inequality, and Violent Crime: A Meta-Analysis of Recent Aggregate Data Studies," Criminal Justice Rev. 18, pp. 182-202.

Idler, Ellen L. and Yael Benyamini. 1997. "Self-rated Health and Mortality: A Review of Twenty-Seven Community Studies," J. Health Soc. Behav. 38, Pp. 21-37.

Jain, Shail B. 1975. Size Distribution of Income: A Compilation of Data. Washington, DC: World Bank.

Jones, Arthur F. and Daniel H. Weinberg. 2000. "The Changing Shape of the Nation's Income Distribution," P60-204, Washington, DC, Bureau of Census. http:/www.census.gov/ftp/pub/hhes/www/p60204.ht $\mathrm{ml}$

Judge, Ken. 1995. "Income Distribution and Life Expectancy: A Critical Appraisal,” Brit. Med. J. 311, pp. $1282-85$.

Judge, Ken and Iain Patterson. 2001. "Poverty, Income Inequality, and Health," work. paper No. 01/29, New Zealand Treasury.

Judge, Ken; Jo-Ann Mulligan and Michaela Benzeval. 1997. "Income Inequality and Population Health," Soc. Sci. Med. 46, pp. 567-79.

. 1998. "Reply to Richard Wilkinson," Soc. Sci. Med. 47, pp. 983-85.

Kahn, Robert S.; Paul H. Wise, Bruce P. Kennedy and Ichiro Kawachi. 2000. "State Income Inequality, Household Income, and Maternal Mental and Phys- ical Health: Cross Sectional National Survey," Brit. Med. J. 321, pp. 1311-15.

Kaplan, George A.; Elsie R. Pamuk, John W. Lynch, Richard. D. Cohen and Jennifer L. Balfour. 1996. "Inequality in Income and Mortality in the United States: Analysis of Mortality and Potential Pathways," Brit. Med. J. 312, pp. 999-1003.

Kaplan, George A. and John W. Lynch. 2001. "Editorial: Is Economic Policy Health Policy?” Amer. J. Public Health 91, pp. 351.

Kawachi, Ichiro, and Tony A Blakely. 2001. "When Economists and Epidemiologists Disagree," $J$. Health. Politics, Policy, Law 26, pp. 533-41.

Kawachi, Ichiro and Bruce P. Kennedy. 1997. "The Relationship of Income Inequality to Mortality: Does the Choice of Indicator Matter?" Soc. Sci. Med. 45, pp. 1121-27.

Kawachi, Ichiro; Bruce P. Kennedy and Deborah Prothrow-Stith. 1997. "Social Capital, Income Inequality, and Mortality," Amer. J. Public Health 87, pp. 1491-98.

Kawachi, Ichiro; Bruce P. Kennedy and Richard G. Wilkinson. 1999. The Society and Population Health Reader: Volume 1: Income Inequality and Health. NY: New Press.

Kennedy, Bruce P.; Ichiro Kawachi and Deborah Prothrow-Stith. 1996a. "Income Distribution and Mortality: Cross-Sectional Ecological Study of the Robin Hood Index in the United States," Brit. Med. J. 312, pp. 1004-07.

Kennedy, Bruce P.; Ichiro Kawachi, Roberta Glass and Deborah Prothrow-Stith. 1998. "Income Distribution, Socioeconomic Status and Self-Rated Health in the United States," Brit. Med. J. 317, pp. 917-21.

Kennedy, Bruce P.; Ichiro Kawachi and Deborah Prothrow-Smith. 1996b. "Important Correction," Brit. Med. J. 312, pp. 1194.

Kitigawa, Evelyn and Philip Hauser. 1973. Differential Mortality in the United States: A Study in Socioeconomic Epidemiology. Cambridge: Harvard U. Press.

Krieger, Nancy. 2001. "Theories for Social Epidemiology in the 21st Century: An Ecosocial Perspective," Int. J. Epidemiology 30, pp. 668-77.

Kunst, Anton; Feikje Groenhof, Johan P Mackenbach and EU Working Group on Socioeconomic Inequalities in Health. 1998. "Occupational Class and Cause Specific Mortality in Middle Aged Men in 11 European Countries: Comparison of Population Based Studies," Brit. Med. J. 316, pp. 1636-42.

Lantz, Paula; James House, J. Lepowski, David Williams, R. Mero and J. Chen. 1998. "Socioeconomic Factors, Health Behaviors, and Mortality," J. Amer. Med. Assoc. 279, pp. 1703-708.

Laveist, Thomas A. 1993. "Segregation, Poverty, and Empowerment: Health Consequences for African Americans," Milbank Quart. 71, pp. 41-64.

Lynch, John; George Davey-Smith, Marianne Hillemeier, Mary Shaw, Trivellore Raghunathan and George Kaplan. 2001. "Income Inequality, Psychosocial Environment and Health: Comparisons across Wealthy Nations," Lancet 358, pp. 194-200.

LeClere, Felicia B. and Mah-Jabeen Soobader. 2000. "The Effect of Income Inequality on the Health of 
Selected US Demographic Groups," Amer. J. Public Health 90, pp. 1892-97.

Leibenstein, Harvey. 1957. Economic Backwardness and Economic Growth. NY: Wiley.

Lindert, Peter H. 2000. "Three Centuries of Inequality in Britain and America," in Handbook of Income Distribution. Anthony B. Atkinson and François Bourguignon, eds. Vol. 1. Amsterdam: North-Holland, pp. 167-216.

Lynch, John W.; George A. Kaplan, Elsie R. Pamuk, Richard D. Cohen, Katherine E. Heck, Jennifer L. Balfour and Irene H. Yen. 1998. "Income Inequality and Mortality in Metropolitan Areas of the United States," Amer. J. Public Health 88, pp. 1074-80.

Lochner, Kim; Elsie R. Pamuk, Diane Makuc, Bruce P. Kennedy and Ichiro Kawachi. 2001. "State-level Income Inequality and Individual Mortality Risk: A Prospective Multilevel Study," Amer. J. Public Health, 91:3, pp. 385-91.

Macintyre, Sally. 1997. "The Black Report and Beyond: what are the issues?" Soc. Sci. Med. 44, pp. 723-45.

Marmot, Michael G. 1994. "Social Differences in Health Within and Between Populations," Daedalus 123, pp. 197-216.

. 2001. "Editorial: inequalities in health," New England J. Med. 345, pp. 134-6.

- 2002. "The Influence of Income on Health: Views of an Epidemiologist," Health Affairs 21, pp. $31-46$.

Marmot, Michael and Martin Bobak. 2000. "International Comparators and Poverty and Health in Europe," Brit. Med. J. 321, pp. 1124-28.

Marmot, Michael G.; H. Bosma, H. Hemingway, Eric Brunner and S. Stansfeld. 1997. "Contribution of Job Control and Other Risk Factors to Social Variations in Coronory Heart Disease Incidence," Lancet 350:9073, pp. 235-9.

Marmot, Michael G.; Martin Shipley and Geoffrey Rose. 1984. "Inequalities in Death-Specific Explanations of a General Pattern," Lancet 1:8384, pp. 1003-1006.

Marmot, Michael G.; George Davey-Smith, S. Stansfeld, C. Patel, F. North, J. Head, I White, Eric Brunner and A. Feeney. 1991. "Health Inequalities among British Civil Servants: The Whitehall II study," Lancet 337:8754, pp. 1387-93.

Massey, Douglas M. 1990. "American Apartheid: Segregation and the Making of the Underclass," Amer. J. Sociology 96, pp. 329-57.

McEwen, Bruce S. 1998. "Protective and Damaging Effects of Stress Mediators: Allostatis and Allostatic load," New England J. Med. 338, pp. 171-79.

McIsaac, Sandra J. and Richard G. Wilkinson. 1997. "Income Distribution and Cause-specific Mortality," Eur. J. Public Health 7, pp. 45-53.

McKeown, Thomas. 1976. The Modern Rise of Population. NY: Academic Press.

- 1979. The Role of Medicine: Dream, Mirage, or Nemesis. Princeton: Princeton U. Press.

McLaughlin, Diane K. and C. Shannon Stokes. 2002. "Income Inequality and Mortality in US Counties: Does Minority Racial Concentration Matter?” Amer. J. Public Health 92, pp. 99-104.
Mealli, Fabrizia and Donald Rubin. 2003. "Commentary: Assumptions Allowing the Estimation of Direct Causal Effects," J. Econometrics, 112, pp. 79-87.

Mellor, Jennifer M. and Jeffrey Milyo. 2001. "Reexamining the Evidence of an Ecological Association between Income Inequality and Health," J. Health, Politics, Policy, Law 26, pp. 487-522.

2002. "Income Inequality and Individual Health: Evidence from the Current Population Survey," J. Human Res., 37, pp. 510-39.

Miller, Douglas. 2000. "Income Inequality and Mortality in the US: Aggregate Data and Micro Relationships," Princeton U. econ. dept., Ph.D. thesis, ch. 1.

Mirrlees, James. 1975. "A Pure Theory of Underdeveloped Economies," in Agriculture in Development Theory. Lloyd Reynolds, ed. New Haven, CT: Yale U. Press.

Mujica, Oscar J.; Carlos Castillo-Salgado, Jorge Bacallao, Enrique Loyola-Elizondo, Maria Christina Schneider, Manuel Vidaurre and George A. O. Alleyne. 2000. "Income Inequality and Suicide Risk in the Americas," Pan-American Health Org.

Murray, Christopher J.L. 1996. "Epidemiologic and Morbidity Transitions in India," in Health, Poverty, and Development in India. Monica das Gupta, Lincoln C. Chen and T. N. Krishnan, eds. Delhi: Oxford U. Press.

Murray, Christopher J.L.; M.C. Michaud, M. McKenna and J. Marks. 1998. "US Patterns of Mortality by County and Race, 1965-94," Cambridge, MA. Harvard Center Population Development Studies.

Murthi, Mamta; Anne-Catherine Guio and Jean Drèze. 1995. "Mortality, Fertility, and Gender Bias in India: A District Level Analysis," Population Devel. Rev. 21, pp. 745-82.

Newhouse, Joseph P. and Lindy Friedlander. 1980. "The Relationship between Medical Resources and Measures of Health: Some Additional Evidence," J. Human Res. 15, pp. 200-18.

Nielsen, Jacob Arendt. 2002. "The Relationship Between Health, Education, and Income: Empirical Evidence," U. Copenhagen dept. econ.

Osler, Merete; Eva Prescott, Morten Grønbœk, Ulla Christensen, Pernille Due and Gerda Engholm. 2002. "Income Inequality, Individual Income, and Mortality in Danish Adults: Analysis of Pooled Data from Two Cohort Studies," Brit. Med. J. 324, pp. $1-4$.

Over, Mead. 1998. "The Effects of Societal Variables on Urban Rates of HIV Infection in Developing Countries: An Exploratory Analysis," in Confronting AIDS: Evidence from the Developing World. European Commission, ch. 2. http://europa.eu.int/comm/ development/aids/limelette/index.htm

Pampel, Fred C. and Vijayan K. Pillai. 1986. "Patterns and Determinants of Infant Mortality in Developed Nations 1950-75," Demography 23, pp. 525-41.

Paukert, Felix. 1973. "Income Distribution at Different Levels of Development: A Survey of Evidence," Int. Lab. Rev. 108, pp. 97-125.

Peña, Rodolfo; Stig Wall and Lars- ke Persson. 2000. "The Effect of Poverty, Social Inequity, and Maternal 
Education on Infant Mortality in Nicaragua, 1988-1993," Amer. J. Public Health 90, pp. 64-69.

Preston, Samuel H. 1975. "The Changing Relation between Mortality and Level of Economic Development," Population Stud. 29, pp. 231-48.

1996 “American Longevity: Past, Present, and Future,” Syracuse U., Maxwell School, Center Policy Research, policy brief 7/1996.

Preston, Samuel H. and Michael R. Haines. 1991. Fatal Years: Child Mortality in Late NineteenthCentury America. Princeton: Princeton U. Press.

Preston, Samuel H. and Paul Taubman. 1994. "Socioeconomic Differences in Adult Mortality and Health Status," in Demography of Aging. Linda G. Martin and Samuel H. Preston, eds. Washington, DC: National Academies Press, pp. 279-318.

Pritchett, Lant and Lawrence H. Summers. 1996. "Wealthier Is Healthier," J. Human Res. 31, pp. 841-68.

Putnam, Robert D., with Robert Leonardi and Raffaella Nanetti. 1993. Making Democracy Work: Civic Traditions in Modern Italy. Princeton: Princeton U. Press.

Ray, Debraj. 1998. Development Economics. Princeton: Princeton U. Press.

Regidor, Enrique; Pedro Navarro, Vicente Dominguez and Carmen Rodriguez. 1997. "Inequalities in Income and Long-term Disability in Spain: Analysis of Recent Hypotheses Using Cross-Sectional Study Based on Individual Data," Brit. Med. J. 319, pp. 898-902.

Roberts, Kevin W. S. 1977. "Voting Over Income Tax Schemes," J. Public Econ. 8, pp. 329-40.

Robson, Arthur. 2002. "Evolution and Human Nature," J. Econ. Perspect. 16, pp. 89-106.

Rodgers, G. B. 1979 "Income and Inequality as Determinants of Mortality: An International Cross-section Analysis," Population Stud. 33, pp. 343-51.

Rogers, Richard G.; Robert A. Hummer and Charles B. Nam. 2000. Living and Dying in the USA: Behavioral, Health, and Social Differentials in Adult Mortality. NY: Academic Press.

Rogot, Eugebe; Paul D. Sorlie, Norman J. Johnson and Catherine Schmitt, eds. 1992. A Mortality Study of 1.3 Million Persons by Demographic, Social, and Economic Factors: 1979-1985 Follow-up. Bethesda: NIH.

Ross, Nancy A.; Michael C. Wolfson, James R. Dunn, Jean-Marie Berthelot, George A. Kaplan and John W. Lynch. 2000. "Relationship between Income Inequality and Mortality in Canada and in the United States: Cross Sectional Assessment Using Census Data and Vital Statistics," Brit. Med. J. 319, pp. 989.

Rosenzweig, Mark. 1988. "Labor Markets in Low Income Countries," in Handbook of Development Economics. Hollis Chenery and T. N. Srinivasan, eds. Vol 1. Amsterdam: North-Holland, pp. 713-62.

Ruhm, Christopher. 2000. “Are Recessions Good for Your Health?” Quart. J. Econ. 115, pp. 617-50.

Sachs, Jeffrey D. 2001. "Tropical Underdevelopment," Cambridge, MA. NBER work. paper 8119.

Sapolsky, Robert M. 1993. "Endocrinology Alfresco: Psychoendocrine Studies of Wild Baboons," Recent Progress in Hormone Research 48, pp. 437-68.
1998. Why Don't Zebras Get Ulcers? An Updated Guide to Stress, Stress-Related Diseases, and Coping. NY: Freeman.

Sawyer, Malcolm. 1976. "Income Distribution in OECD Countries," OECD Economic Outlook, Occasional Studies. Paris, OECD.

Schofield, Roger and David Reher. 1991. "The Decline of Mortality in Europe," in The decline of mortality in Europe. Roger Schofield, David Reher and Alain Bideau, eds. Oxford: Clarendon Press, pp. 1-17.

Sen, Amartya K. 1973. On Economic Inequality. Oxford: Clarendon Press.

1999. Development as Freedom. NY: Knopf.

Shibuya, Kenji; Hideki Hashimoto and Eiji Yano. 2002. "Individual Income, Income Distribution, and Selfrated Health in Japan: Cross-Sectional Analysis of Nationally Representative Sample,"Brit. Med. J. 324 , pp. 1-5.

Smedley, Brian D.; Adrienne Y. Stith and Alan R. Nelson, eds. 2002. Unequal Treatment: Confronting Racial and Ethnic Disparities in Health Care. Institute of Medicine, Washington, DC: National Academy Press.

Smith, James P. 1999. "Healthy Bodies and Thick Wallets: The Dual Relation between Health and Economic Status," J. Econ. Perspect. 13, pp. 145-66.

Soobader, Mah-Jabeen and Felicia LeClere. 1999. "Aggregation and Measurement of Income Inequality: Effects on Morbidity," Soc. Sci. Med. 48, pp. $733-44$.

Stanistreet, Debbie; Alex Scott-Samuel and Mark A. Bellis. 1999. "Income Inequality and Mortality in England," J. Public Health Med. 21, pp. 205-207.

Steckel, Richard. 1995. "Stature and Standard of Living," J. Econ. Lit. 33, pp. 1903-40.

Stiglitz, Joseph E. 1976. "The Efficiency Wage Hypothesis, Surplus Labor, and the Distribution of Income in L.D.C.s," Oxford Econ. Papers 28, pp. 185-207.

Strauss, John and Duncan Thomas. 1998. "Health, Nutrition, and Economic Development," J. Econ. Lit. 36:2, pp. 766-817.

Sturm, Roland and Carole Roan Gresenz. 2002. "Relations of Income Inequality and Family Income to Chronic Medical Conditions and Mental Health Disorders: National Survey," Brit. Med. J. 324, pp. $1-5$.

Subramanian, Shankar and Angus Deaton. 1996. "The Demand for Food and Calories," J. Polit. Econ. 104, pp. 133-62.

Swamy, Anand V. 1997. "A Simple Test of the Nutrition-based Efficiency Wage Model,"J. Devel. Econ. 53, pp. 85-98.

Sydenstricker, Edgar and Willford I. King. 1921. "The Measurement of the Relative Economic Status of Families," Quart. Pub. Amer. Statist. Assoc. 17, pp. 842-57.

Szreter, Simon. 1988. “The Importance of Social Intervention in Britain's Mortality Decline c. 1850-1914: A Reinterpretation of the Role of Public Health," Soc. Hist. Med., 1, pp. 1-37.

Victora, Cesar G.; J. Patrick Vaughan, Fernando C. Barros, Anamaria C. Silva and Elaine Tomasi. 2000. "Explaining Trends in Inequities, Evidence from 
Brazilian Child Health Studies," Lancet 356, pp. 1093-98.

Wagstaff, Adam. 2000. "Socioeconomic Inequalities in Child Mortality: Comparisons across Nine Developing Countries," Bull. World Health Org. 78, pp. $19-29$.

12002. "Poverty and Health," Bull. World Health Org., 80, pp. 97-105.

Wagstaff, Adam and Eddy van Doorslaer. 2000. "Income Inequality and Health: What Does the Literature Tell Us?" Annual Rev. Public Health 21, pp. 543-67.

Walberg, Peter; Martin McKee, Vladimir Shkolnikov, Laurent Chenet and David A. Leon. 1998. "Economic Change, Crime, and Mortality Crisis in Russia: Regional Analysis," Brit. Med. J. 317, pp. 312-8.

Waldmann, Robert J. 1992. "Income Distribution and Infant Mortality," Quart. J. Econ. 107, pp. 1283-302.

Wennemo, Irene. 1993. "Infant Mortality, Public Policy and Inequality-a comparison of 18 industrialized countries, 1950-1985," Sociology Health Illness 15 , pp. $429-46$.
Wilkinson, Richard G. 1989. "Class Mortality Differentials, Income Distribution and Trends in Poverty 1921-1981," J. Soc. Policy 18, pp. 307-35.

1921. 1992. "Income Distribution and LifeExpectancy," Brit. Med. J. 304, pp. 165-68.

. 1994. "The Epidemiological Transition: From Material Scarcity to Social Disadvantage?" Daedalus 123 , pp. 61-77.

. 1996. Unhealthy Societies: The Affliction of Inequality. London: Routledge.

- 1997. "Commentary: Income Inequality Summarizes the Health Burden of Individual Relative Deprivation," Brit. Med. J. 314, pp. 1727-28.

. 1998. "Letter to the Editor," Soc. Sci. Med. 47, pp. 411-12.

. 2000. Mind the Gap: Hierarchies, Health, and Human Evolution. London: Weidenfeld and Nicolson.

Wolfson, Michael C.; George A. Kaplan, John W. Lynch, Nancy A. Ross and Eric Backlund. 1999. "Relationship between Income Inequality and Mortality: Empirical Demonstration," Brit. Med. J. 319, pp. 953-55.

Yitzhaki, Shlomo. 1979. "Relative Deprivation and the Gini Coefficient," Quart. J. Econ. 93, pp. 321-4. 